\title{
LOS PAISAJES CULTURALES DEL NOROESTE DE CHIHUAHUA: LA REGIÓN Casas Grandes-Paquimé
}

FEDERICO J. MANCERA-VALENCIA ${ }^{1}$

\section{RESUMEN}

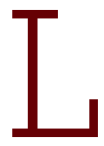
os paisajes culturales son producto del uso y manejo de los ecosistemas, que se manifiestan en patrimonios culturales materiales, inmateriales y bioculturales. La producción de los paisajes culturales es una complejidad transdisciplinaria de tipo geográfico, cultural, ambiental, histórico y político. Se presentan criterios teórico-metodológicos para el análisis de los paisajes culturales del semidesierto, desierto y bosques templados secos de Chihuahua. Se expone el caso de la región noroeste o Casas-Grandes-Paquimé (Galeana, Nuevo Casas Grandes, Casas Grandes-Madera y Janos).

Palabras clave: paisajes culturales, patrimonio cultural, transdisciplinariedad.

1 Geógrafo de la Facultad de Filosofía y Letras. Maestro en Educación. Doctor en Pedagogía Crítica. Miembro del Sistema Nacional de Investigadores Nivel I. Profesorinvestigador del Centro de Investigación y Docencia. Líder del Cuerpo Académico Desarrollo y Gestión Intercultural en Educación. Sus líneas de investigación son: Patrimonio cultural y biocultural, Gestión y desarrollo intercultural, Estudios culturales y educación patrimonial, Geografía histórica y cultural, Poscolonialismo y Filosofía intercultural en educación y pensamiento complejo. 


\begin{abstract}
Cultural landscapes are product of the use and management of ecosystems, which are manifested in material, immaterial and biocultural heritage. The production of cultural landscapes is a transdisciplinary complex of geographical, cultural, environmental, historical and political nature. Theoretical-methodological criteria for the analysis of cultural landscapes of semi-desert, desert and dry temperate forests of Chihuahua are presented. The case of the Northwest region or Casas-Grandes-Paquimé (Galeana, Nuevo Casas Grandes, Casas Grandes-Madera and Janos) is presented.
\end{abstract}

Keywords: cultural landscapes, cultural heritage, transdisciplinarity.

\title{
LOS PAISAJES CULTURALES DEL SEPTENTRIÓN
}

Cabe destacar que los espacios del norte de México, donde la influencia de su extensión territorial, los ecosistemas que los caracterizan, así como la forma en la que los grupos humanos se apropian de ellos, nos permiten afirmar que se generan estrategias distintas de orden político, social, económico y cultural, especialmente en ámbitos rurales, donde el uso y manejo del agua resultó fundamental para consolidar la apropiación y producción del territorio, así como el desarrollo de formas sociales y económicas, que en conjunto permitieron mantener "cambios dilatados" en la ocupación de dichos espacios, junto con otras estrategias como las encomiendas, repartimientos, presidios y misiones.

A estas últimas formas políticas y socioeconómicas, se suman las que proporcionaron los bienes materiales de subsistencia, como las diversas arquitecturas y sistemas hidráulicos ${ }^{2}$ que usaron y manejaron distintos humedales, aportando agua, aun en la actualidad, a huertos y hortalizas, y a dispersos centros de población rural y urbano-rural, los cuales, mediante procesos históricos de larga duración, se constituyen, entre otros, en elementos culturales, es

2 Nos referimos a las acequias, acueductos, estanques, jagüeyes, norias, pozos, presas de levante, gaviones, galerías filtrantes, pozos de absorción, etcétera. 
decir, las bases que dieron sentido a la producción y construcción de paisajes culturales dentro del desierto chihuahuense.

Derivado de lo anterior, resulta ineludible evaluar que existen paisajes culturales norteños que se caracterizan por procesos dilatados en los que - sin que implique la ausencia de inestabilidad e incertidumbre sociohistórica-, observados desde una perspectiva de larga duración, hay elementos culturales que perduran, subsisten, o bien, poseen trasformaciones que permiten su conservación, manteniéndose con un esquema de sustentabilidad, como sería el sistema de acequias y huertos distribuidos en todo el estado de Chihuahua, y que se presentan también en el estado vecino de Nuevo México, Estados Unidos, los cuales pueden considerarse como parte de la historia ambiental y de la ecología cultural de este extenso territorio.

\section{INTERPRETACIÓN Y COMPLEJIDAD DE LOS PAISAJES CULTURALES: CONSIDERACIONES TEÓRICAS-METODOLÓGICAS}

La comprensión de los paisajes como construcción sociocultural tiene una gran importancia para el análisis de las culturas del desierto, dado que en la actualidad el estudio de la diversidad biológica y cultural del territorio chihuahuense cuestiona las formas en las que se impulsan los principios de sustentabilidad, lo que requiere de categorías de análisis de complejidad transdisciplinaria que se puedan sobreponer a las clásicas especializaciones y parcelarismos científicos.

Las variables o indicadores culturales son insoslayables, principalmente ahora que se requiere evaluar y proteger los recursos naturales y culturales. Algunos de ellos son concebidos como Patrimonio de la Humanidad y de las naciones a las que pertenecen y que posibilitan, sin duda, otras formas de desarrollo regional. En específico, las relaciones entre los seres humanos y la naturaleza de Chihuahua son muy estrechas. Hay que entenderlas como un vínculo de complejidad territorial, como en el caso de los paisajes culturales, noción que implica comprender que no hay ser humano fuera de la naturaleza ni de la cultura. 


\section{LOS PAISAJES CULTURALES COMO COMPLEJO EPISTEMOLÓGICO TRANSDISCIPLINARIO}

El concepto de paisaje cultural como proceso de explicación científica, es asignado históricamente a las ciencias geográficas (Luis, 1980; Mateo, 1982). Sin embargo, se ha diversificado su uso, el cual se ha desarrollado y pulido metodológicamente por múltiples disciplinas. En la actualidad, los paisajes culturales posibilitan incluir de forma integral los fenómenos geográficos, históricos, políticos, culturales y ambientales o bioculturales al estudio y protección regional del patrimonio cultural. Permiten el diseño de políticas públicas transversales para el desarrollo territorial y sustentable de las regiones (véase: Idesmac, DCAAAC, Allinfo, 2018). Esto ha gestado la emergencia de nuevas propuestas metodológicas -más allá de usos de vectores, indicadores y lógicas cuantitativos-, que identifican y desarrollan diversas estrategias transdisciplinarias para la compresión de la complejidad social y humana de los paisajes. Para 2019, hay múltiples experiencias y resultados de investigación en relación con los paisajes culturales.

A continuación, se describirán estudios y autores clásicos de los paisajes culturales, específicamente de aquellos que considero dan aportaciones a los paisajes del desierto.

Hay dos grandes itinerancias científicas por el estudio de los paisajes: la primera se dirige al interés de tipo físico-natural, cuya tradición reside en la geografía física y la aplicación de la teoría de sistemas (Riábchikov, 1976; Mateo, 1982), a la cual se suma el desarrollo de estudios interdisciplinarios de la geomorfología y la ecogeografía (Tricart, \& Killian, 1982; Bertrand, 1987; Geissert, \& Rossignol, 1987; Cervantes, 1993; Mateo, \& Ortiz; 2001). El conjunto de esta línea de investigación resulta abundante y con un sentido de aplicación en el desarrollo rural y en el manejo y gestión de desastres socionaturales. A estas escuelas, se suman aportaciones singulares de la biología y la ecología (Forman, 1995; Giddings, Chiappy, Soto, \& Gama, 1995).

La segunda itinerancia científica social y humanista, es la que se vincula a "la geografía cultural", interpretada como enfoque y 
no como rama de las ciencias geográficas (Fernández, 2005; Romero, 2001), y llegándose a integrar estas interpretaciones o ramas con importantes y singulares investigaciones, lejos de la exclusividad geográfica. Por ello, dan resultados transdisciplinarios de comprensión y explicación de complejidad cultural y ambiental de los paisajes (Capel, 2002; Hoffmann, 1993; Barragán, Ortiz, \& Toledo, 2007; García, Jiménez y Thiébault, 2008). Esta itinerancia de la geografía cultural, se alimenta de las explicaciones e interpretaciones del paisaje, que ofrecen diversas disciplinas; por ejemplo:

a) Arqueología. Los estudios de paisaje en arqueología están íntimamente ligados a investigación de paleontología y procesos culturales. En México, los estudios se han concentrado en la región cultural mesoamericana, sean estos de tipo paleobotánico, paleoedafológico, paleoclimático, paleogeográfico o paleolacustre (Sauer, 1925, 1931; West, 1979; MacCloung, \& Tapia, 1995; MacCloung, 1984; Gamboa, \& Mancera-Valencia, 2008).

b) Historia. Los paisajes son, sin duda, un tema de gran tradición para los historiadores y son múltiples los estudios al respecto, no así de los geógrafos, sobre todo en México. Estos últimos se han inclinado más hacia el aspecto ambiental y de la geografía física. Actualmente, existe una línea interdisciplinaria muy de moda: la historia ambiental, a la que se suman de manera integral la geografía histórica regional y local, y la historia de las ideas; de igual manera, la historia de las trasformaciones del espacio rural-urbano y urbano. En cualquier sentido, estas historias se vinculan fuertemente con la conceptualización y análisis de la construcción y producción de los paisajes (Sauer, 1941; Braudel, 1969, 1991, 1997; Le Roy, 1978; Cramaussel, 1989; Tortolero, 1996; García Martínez, 1997, 1998, 2003; Urquioloa, 1999; Arnold, 2000; González de Molina, \& Martínez, 2001; Capel, 2002).

c) Antropología. El concepto y análisis regional, territorialidad, desarrollo, análisis cultural del espacio y la apropiación simbólica de la naturaleza son de los temas más re- 
currentes en la antropología, en el análisis de los paisajes, cuyos aportes son de gran importancia. Las tendencias actuales van desde el diseño de metodologías de lectura del paisaje hasta antropología del desierto, estudios que, sin duda, influyen o se suman a la recuperación y renovación de la geografía cultural en México (Hirich, \& O’Hanion, 1995; Brown, 1999; Boehm, 2001, 2005; Fernández, 2005; Fábregas, 1992, 2003; De la Peña, 1991; Pérez-Taylor, Olmos, \& Salas, 2007).

d) Sociología. Desde este ángulo, los criterios que pueden aportar al análisis de los paisajes están relacionados con el estudio de construcciones sociales de la realidad (Berger, \& Luckmann, 2001), que permiten vislumbrar que, más allá de una perspectiva objetiva de creación del paisaje, es decir, desde el análisis del discurso de la modernidad y la producción (Baudrillard, 1983), está referido también al análisis de riesgo (Luhmann, 1998; Douglas, 1996) como problema sociológico en el que se pone en evidencia no solo la perspectiva objetiva de la producción rural, sino, al mismo tiempo, perspectivas subjetivas de funcionalidad social y de conocimiento del territorio, lo cual permite vislumbrar que los paisajes culturales en el semidesierto responden a formaciones culturales objetivas y subjetivas, y que, al articularse, se gestan discursos inequívocos, irrefutables y productivamente probados que impiden deconstruir (León, 2001), y, por tanto, construir propuestas distintas, como sería el caso de las conversiones productivas en el desierto, donde el desarrollo no se funda a partir del agua.

e) Psicología. Sin duda, su vinculación con los paisajes está referida a la percepción y a la comprensión socioambiental dentro de contextos urbanos o rurales, desarrollando el estudio de imágenes mentales y semióticas (Gould, 1975; Brumet, 1974; Dansereau, 1981). Actualmente, resultan fundamentales los estudios de la representación social en los que se articulan aportaciones de la psicología social, 
así como de la historia de las mentalidades y de la cultura, los cuales pueden aportar singulares criterios interpretativos (prácticas sociales, discurso, narraciones) para el análisis de los paisajes culturales (Tinoco, \& Bellato, 2006; Ruiz, 2003; Rodríguez, 2003; Jodelet, 2016; Moscovici, 1985; Olmos, 2001).

f) Humanidades. Desde la perspectiva de las disciplinas humanísticas, las bellas artes, como la arquitectura, ${ }^{3}$, ofrecen aportes interpretativos estéticos y afectivos hacia el paisaje (Jellicoe et al., 1995; Gónzalez, 1985), la literatura y la pintura (Fernández, \& Garza, 2006; Ojeda, 2005; Gómez de Liaño, 1990; More et al., 1996); la fotografía, el cine, el teatro, la música, por su parte, ofrecen desde su interpretación formas de conocimiento hacia los paisajes que influyen no solo para la creación artística, sino también para un imaginario social de los mismos. Además, resulta importante mencionar que desde la posibilidad creativa de las artes existe una articulación de múltiples disciplinas manifestando formas innovadoras transdisciplinarias.

g) Gestión del patrimonio. Otra línea del estudio de los paisajes, tal vez la más integral y de análisis de complejidad, es aquella que está vinculada a la gestión y desarrollo regional del patrimonio cultural, que motiva el interés de organismos internacionales de protección del patrimonio cultural; tal es el caso de la Unesco, Icomos y la FAo (Unesco, 2003).

Los paisajes culturales posibilitan la integración de diversidad patrimonial en los ejes de la historia y la geografía regionales. En 1972, la Unesco, a través de la Convención del Patrimonio Mundial, creó un instrumento internacional único que reconoce y protege el patrimonio cultural y natural, incluyendo así la relación sociedadnaturaleza como una categoría integral de patrimonio mundial. No obstante, es hasta 1992 en que dicho comité realiza revisiones a

3 Desde la arquitectura existen varias líneas y propuestas que resultan importantes, así como significativos criterios estéticos y de planificación para este tema del análisis de los paisajes. 
los criterios culturales y ambientales de la Guía Operativa para la Implementación de la Convención del Patrimonio Mundial, y se incorpora la categoría de Paisajes culturales. De esta manera, se posibilita a los paisajes culturales integrarse a las nominaciones de la Lista de Patrimonio Mundial (Mujica, 2000; Rössler, 2002).

Resultado de este proceso fue la motivación de múltiples reuniones que identificaron diversas categorías de paisajes culturales en el mundo, lo que ha permitido diversificar el criterio y ampliar las perspectivas de protección y gestión del patrimonio cultural local y regional. En el fórum "Unesco: Universidad y patrimonio" (2005), realizado en la Universidad de Newcastle (Upon Tyne), se llevó a cabo la interconferencia "Paisajes en el siglo xxl", en la que se abordaron siete temas que muestran la diversificación y alcance temático de su estudio:
a) Paisajes culturales, museos y patrimonio (tangible e intan- gible);
b) Paisajes culturales y cultura visual;
c) Paisajes culturales, identidades y comunidades;
d) Paisajes culturales, turismo y economía;
e) Paisajes culturales y arquitectura;
f) Paisajes culturales y educación; y
g) Paisajes culturales, gestión y protección.

Por otra parte, en México, la Cámara de Diputados, en su LXIII Legislatura, propuso la iniciativa con proyecto de decreto para agregar en la categoría de Áreas naturales protegidas el concepto de "Paisajes bioculturales, definiéndolo como áreas de protección natural "que se constituyen en aquellos territorios que comparten un paisaje que pueden presentar cualquiera de las características y elementos biológicos y culturales señalados" (Comisión de Medio Ambiente y Recursos Naturales, LXIII Legislatura). Por su parte, en el estado de Chihuahua, México, la Ley para la Protección del Patrimonio Cultural (2018) considera dos áreas de protección o declaradas vinculadas a los paisajes: 
a) Paisaje histórico urbano: "Los sectores urbanos de edificios homogéneos en cuanto a su tipología y ligados a la historia de un grupo social".

b) Paisaje biocultural: "Son resultado de la integración de factores ecológicos, sociales y culturales, producto de la constante actividad humana sobre elementos naturales, que están íntimamente relacionados con la creación y recreación de identidades culturales. De esta manera, el paisaje biocultural está conformado por comunidades agroecológicas y ecosistemas naturales que configuran el agroecosistema. Es una unidad de biodiversidad y cultura sobre la cual pueblos milenarios y campesinos cimentan su permanencia cultural y su desarrollo como grupo. Es un sistema complejo e interdependiente donde se encuentra y recrea el patrimonio biocultural".

Los paisajes bioculturales serán, para la segunda mitad del siglo xXI, un gran desafío de la historia ambiental, cultural y agroalimentaria del planeta Tierra (Sipam, 2002). Por ello, se gestan protocolos para la implementación de los paisajes bioculturales (Graff-Montero, Anta-Fonseca, Bezaury-Creel, \& Arellano-Guillermo, 2015), pues están en juego patrimonios inmateriales de sociedades y comunidades campesinas e indígenas, rural-urbanas, la biodiversidad y los ecosistemas, el desarrollo territorial y sustentable, la educación patrimonial y ambiental, y, con la necesaria búsqueda de estrategias inéditas para el desarrollo humano sostenido, el buen vivir ${ }^{4}$ de las sociedades.

4 Existe una variedad amplia de definiciones y acepciones del término "buen vivir"; de hecho, una de sus características es su estado permanente de construcción, cuya idea invoca más a una plataforma que a un concepto acabado y preciso. Sin embargo, existen dos elementos comunes en ellos: a) Se posiciona abiertamente como una alternativa a la visión moderna de progreso encarnada en el ideal de desarrollo; b) Implica un rescate de las epistemologías y cosmovisiones de los pueblos indígenas, sobre todo de la región andina, encarnadas en el Sumak Kawsay quechua o el Suma Qamaña aymara; c) Y, por último, implica también considerar un cambio de paradigma antropocéntrico imperante en los modelos de desarrollo occidental, para apostar, en cambio, por un paradigma biocéntrico que implica reconocer una forma diferente de vivir y concebir la naturaleza y realidad(es) (Loera, 2015). 
Es absurdo definir una metodología ante un problema que epistemológicamente rebasa las propuestas metodológicas disciplinarias. Por eso, la explicación y comprensión de la construcción de los paisajes culturales debe procurar la transdisciplinariedad y estar contextualizados. Por ello, es de considerarse en el estudio de los paisajes culturales de los territorios del desierto y semidesierto, así como de zonas con bosques templados secos, del estado de Chihuahua, las siguientes características:

1. Definen límites o fronteras a los entornos naturales continuos, es decir, una geopolítica o control y vigilancia humana del espacio y a través del tiempo.

2. Se desarrollan apropiaciones y transformaciones de los ecosistemas mediante el trabajo o uso y manejo de sus elementos (flora, fauna, suelo, clima, agua, relieve), integrándolos a sus sistemas simbólicos, emotivos y de necesidades haciendo un patrimonio biocultural.

3. Se gestan saberes por el proceso de apropiación de los ecosistemas, para el uso y manejo de sus elementos y la satisfacción del sistema de necesidades del orden material e inmaterial (corpus-praxis-animus-psique del patrimonio biocultural) ${ }^{5}$

4. Se desarrollan formas de organización social y con fines de producción de mercancías, formando gobernanza, elemento de cohesión social, formalización y surgimiento de reglamentos o sistemas jurídicos consuetudinarios de carácter colectivo fundamentales para el uso y manejo de los recursos naturales.

5. Se gestan procesos rituales, simbólicos y de lenguaje en torno a los recursos naturales.

5 El patrimonio biocultural (patrimonio inmaterial-material) está constituido por bienes culturales que se alimentan y sustentan de conocimientos y saberes tradicionales (epistemologías) construidos y practicados por procesos complejos de racionalidades étnicas. Donde las emociones (psique) son parte de la lógica de la racionalidad, al igual que lo espiritual (animus) como fuerza de creación e innovación constante ante las incertidumbres de la vida y de las prácticas productivas (praxis). Todos concatenados gestan procesos intelectualizados (corpus) en ambientes colectivos o comunitarios, certificados, producidos, distribuidos e intercambiados, a través de lenguajes propios que dan sentido ontológico a los ecosistemas y a las manifestaciones generales de la naturaleza (Mancera-Valencia, 2016). 
6. Se crean espacios y tiempos sagrados vinculados a elementos de los ecosistemas y sus ritmos biológicos interrelacionados a los alimentos.

7. Se constituyen los elementos del paisaje cultural como parte intrínseca de la existencia de grupos, de posibilitador de identidades colectivas y de significancia psicosocial.

De esta manera, los paisajes culturales articulan, objetiva y subjetivamente, la concatenación entre la cultura y la naturaleza, y nos ilustran el dinamismo de la sociedad y los asentamientos humanos, a través de la historia y la geografía del territorio, con la influencia de las presiones o desventajas presentadas por su medioambiente y las fuerzas socioeconómicas sucesivas, que pueden ser, en ambas, internas o externas, provocando cambios culturales y ambientales constantes y complejos.

Los paisajes culturales no pueden estar limitados a los intereses de la investigación básica que impulsan las diversas disciplinas que están interesadas en estudiarlos. En cambio, deben ser considerados en el marco del desarrollo territorial y regional. Esto es posible cuando este es considerado como recurso, bien y producto cultural, es decir, patrimonio cultural, que puede entrar al mercado desde un marco jurídico de protección, conservación y educación ambiental-patrimonial específica.

Los paisajes culturales deben ser evaluados por su valor universal excepcional y de su representatividad en términos de región geocultural, claramente definida, y de su capacidad para mostrar los elementos culturales esenciales y distintos de una zona; por lo tanto, y de acuerdo con la dimensión subjetiva y objetiva de los pueblos, pueden ser considerados patrimonio cultural.

\section{INDICADORES DE LOS PAISAJES CULTURALES}

En la comprensión de los paisajes culturales, se requieren indicadores que permitan demostrar que su conjunto genera formaciones patrimoniales materiales, inmateriales y naturales, de tal 
forma que dan sentido estructural a los paisajes. Los indicadores ${ }^{6}$ son entendidos como concentradores y atractores de procesos (históricos-geográficos-sociales-políticos-ambientales) y de escala local-regional. Metodológicamente, la estrategia es recurrir al análisis de los procesos sociohistóricos, geohistóricos y ambientales para observar cómo se reflejan concatenados en la ocupación del territorio y se constituyen como elementos significativos de los paisajes. Esta estrategia metodológica requiere de trabajo y recorridos de campo, múltiples entrevistas, elaboración de mapas y fotografías, revisión de archivos y documentos regionales, de modo que mediante la síntesis se identifican los indicadores del paisaje cultural en el semidesierto y los bosques templados secos de Chihuahua, los cuales son:

\section{Los humedales ${ }^{7}$ y la unidad hídrica local y regional. \\ 2. Unidades geomorfológicas.}

6 Hugo Zemelman (1989), en su Crítica epistemológica de los indicadores, plantea que el "indicador [es la] problemática de las relaciones establecidas entre la realidad y la representación". Afirma que el reto del indicador no es considerarlo como una simple "variable aislada [que] puede representar objetivamente al conjunto de procesos que concurren en la formación constitutiva de un fenómeno", es decir, hay que considerar que la realidad es parte de la significancia del indicador y, a esta realidad, hay que tomarla en cuenta como "una síntesis del pasado y posibilidades del futuro en el presente; esto es como lo dado que contienen lo porvenir". Los paisajes culturales son "condensadores de historicidad" y con doble acepción "como fruto del pasado y como presente que contiene las posibilidades del futuro".

7 Los humedales albergan abundante diversidad biológica. Se encuentran en todo el mundo, desde los trópicos hasta las llanuras heladas, y son tan esenciales para el bienestar del planeta como cualquier otra zona ecológicamente equilibrada. "Los humedales son ecosistemas muy productivos, que proporcionan casi dos tercios de la pesca mundial. Se pueden encontrar bajo distintas formas: marismas, estuarios, bancos fangosos, lechos fluviales, estanques, pantanos, deltas, arrecifes de coral, Ciénegas, lagunas, mares poco profundos, turberas, lagos y llanuras aluviales" (WwF, 1996). En 1971, la Convención de Ramsar sobre los Humedales (Ramsar, Irán, 1971) proporcionó el marco de cooperación internacional para conservar y usar inteligentemente los recursos y la diversidad biológica de los humedales, además de los apoyos necesarios para reunir a especialistas en el diseño de un sistema para la clasificación de tipos de humedales, la cual comprende treinta y cinco tipos que pueden presentarse en todo el mundo. En Chihuahua, se pueden identificar veinticuatro, muy similares a los existentes en otros desiertos de la geografía terrestre (véase: Mancera-Valencia, 2016). 
3. Ecosistema local o regional, constituido por complejos procesos de intercambio y articulación entre el clima-suelo-vegetación-relieve-flora-fauna.

4. Asentamientos prehispánicos o prehistóricos, acequias, casashabitación, casas-acantilado, misiones, presidios, conjuntos urbanos, jardines o parques, que se constituyen como elementos patrimoniales edificados.

5. Material cultural arqueológico o histórico, petrograbados y pinturas rupestres, patrimonio documental como archivos, fotografías, partituras, bienes muebles escolares, arte sacro, utensilios del patrimonio gastronómico, recetas, entre muchos otros que puedan considerarse como elementos patrimoniales muebles e inmuebles.

6. Elementos culturales ${ }^{8}$ como saberes y prácticas tradicionales, formas de organización social, códigos, simbolismo y lenguajes; rituales y eventos ceremoniales; procesos emotivos colectivos, entre otros. Se conforman como patrimonios inmateriales.

7. Procesos culturales en el territorio que marquen un carácter significativo en el paisaje, como marcas o sellos de procesos de cazadores-recolectores, agrícolas, urbanos, de industrialización, otras actividades productivas, tecnologías, institucionalización de las actividades humanas, servicios colectivos, de inmigrantes, por procesos jurídicos que impacten en el territorio, entre otros.

8 Los entendemos desde la perspectiva de Guillermo Bonfil Batalla (1992) como "los recursos de una cultura que resulta necesario poner en juego para formular y realizar un propósito social. Pueden distinguirse, al menos, las siguientes clases de elementos culturales: a) materiales, tanto naturales como los que han sido trasformados por el trabajo humano; b) de organización, que son las relaciones sociales sistematizadas a través de las cuales se realiza la participación; se incluyen la magnitud y las condiciones demográficas; c) de conocimiento, es decir, las experiencias asimiladas y sistematizadas y las capacidades creativas; d) simbólicos: códigos de comunicación y representación, signos y símbolos; e) emotivos: sentimientos, valores y motivaciones compartidos; la subjetividad como recurso" (p. 50). 


\section{PARÁMETROS DE COMPRENSIÓN DE LOS PAISAJES CULTURALES}

Los anteriores indicadores permiten explicar y configurar socioambiental y culturalmente al paisaje y a la diversidad patrimonial que conforman. No obstante, hay paramentos o criterios de discusión y análisis para la comprensión y explicación de la construcción de los paisajes culturales de la región estudiada. Estos parámetros se pueden presentar de forma simultánea y diacrónica. Existen factores que pueden predecir las transformaciones del paisaje, como el cambio climático, o bien, las acciones locales-regionales de las sociedades sobre el territorio. Es por eso que se considera importante evaluar:

1. La historicidad del lugar. Desde una perspectiva de larga duración y perduración de prácticas objetivas y subjetivas locales, considerando las categorías oficiales de temporalidad: periodo prehispánico, histórico y artístico-contemporáneo, y su sobreposición o traslape territorial.

2. La espacialización de procesos histórico-culturales interrelacionados con otras regiones, derivados de los intercambios económicos y de mercancías, por definiciones políticas y jurídicas por procesos migratorios.

3. Procesos de cambio, devenidos de procesos internos como externos o combinados, que se manifiestan en este territorio como amenazas, oportunidades, fortalezas o debilidades para colonización u ocupación del territorio.

4. Las formas de apropiación de los ecosistemas de manera tradicional y moderna para el desarrollo de las actividades productivas.

5. Las formas de adaptación y equilibrio entre los ecosistemas y las necesidades humanas, como el equilibrio cultura-naturaleza en la producción de mercancías y las formas de inequidad y exclusión social en la apropiación de los ecosistemas.

6. Diversificación genética y cultural, que implica biodiversidad y germoplasma, huertos, nichos ecológicos, así como tradicio- 
nes gastronómicas y bioculturales que se derivan del desarrollo de la gobernanza biocultural.

\section{REGIÓN NOROESTE DE CHIHUAHUA O REGIÓN CASAS GRANDES- PAQUIMÉ}

Tal vez por ser un área muy estudiada desde la perspectiva arqueológica, la región chihuahuense del noroeste, Casas GrandesPaquimé, tenga el más alto nivel de importancia para este periodo prehispánico, razón por la que se considera como una zona singular en el septentrión mexicano. También porque a lo largo del tiempo ha mantenido de manera contante diversos procesos productivos-históricos-culturales, que han modificado los ecosistemas, base de las actividades primarias que hasta ahora subsisten como dominantes. Por lo anterior, en el presente trabajo se menciona la región del noroeste de Chihuahua o región Casas Grandes-Paquimé (Galeana, Nuevo Casas Grandes, Casas Grandes, Madera y Janos) como unidad territorial, sometida a diversos procesos históricos-culturales-productivos, que dan sentido a los paisajes culturales de la zona (véase Mapa 1). 
Mapa 1. Paisajes culturales de la región noroeste de Chihuahua o región Casas Grandes-Paquimé.

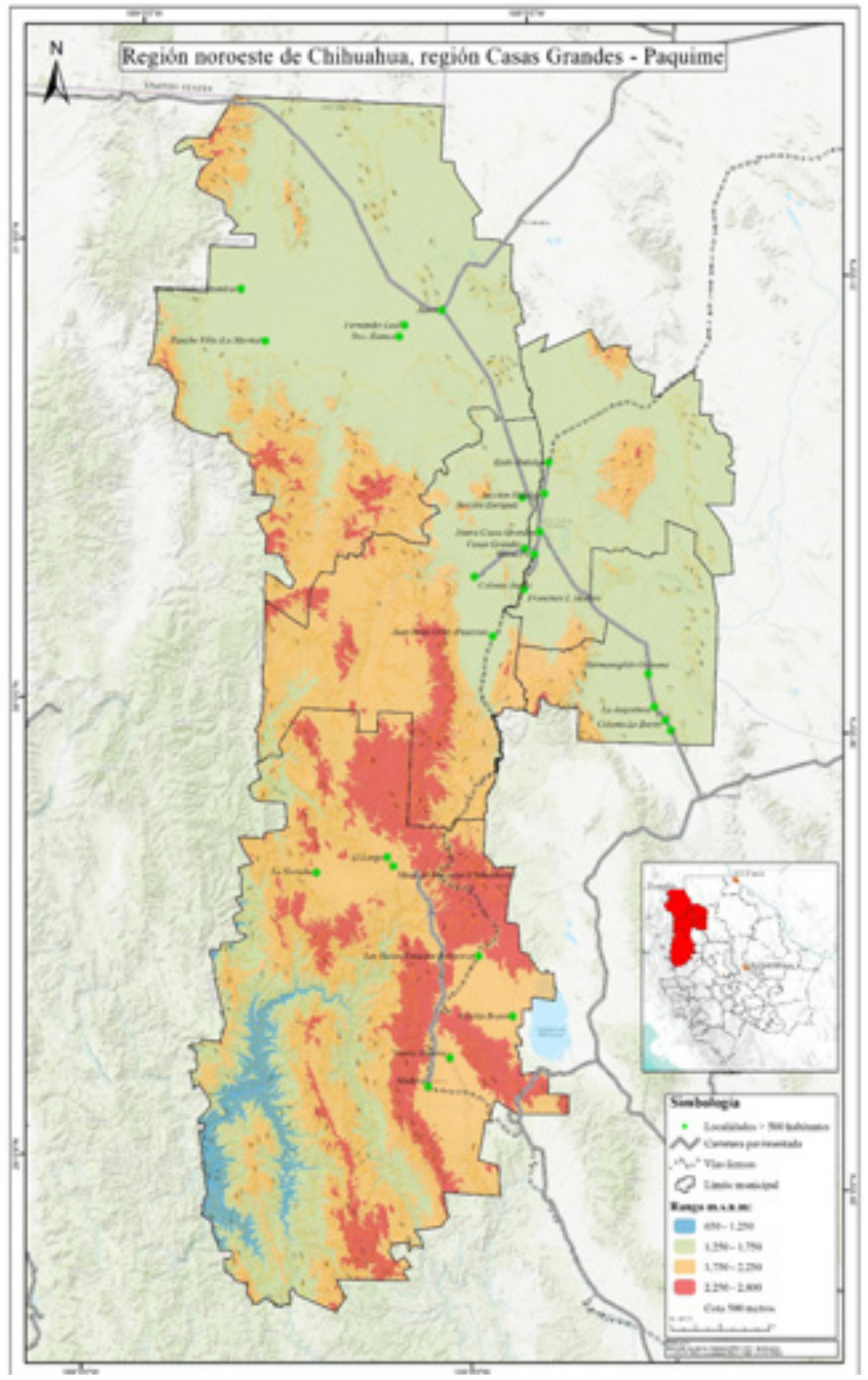

Fuente: elaboración propia con base en el Inegi (2014). 
Es importante tener presente que el área de estudio, se encuentra irrigada por las corrientes superficiales de los ríos Casas Grandes, Papigochi, Gavilán y Tutuaca. Una de sus vertientes, se escurre en el semidesierto con grandes extensiones de diversas unidades vegetativas, así como en bosques de pino-encino, encino, praderas con diversos tipos de pastos y chaparrales. La influencia ecosistémica de los bosques templado-secos de la sierra Tarahumara (municipio de Madera), es notable para las culturas prehispánicas.

En estos elementos ambientales, se desarrollaron humedales en condiciones geomorfológicas y ecogeográficas específicas de gran importancia regional:

1. Llanuras de acumulación pie de monte;

2. Llanuras aluviales;

3. Zonas de acumulación y sedimentación de materiales aluviales.

4. Planicies y llanuras con praderas ricas en pastos;

5. Cuencas endorreicas (bolsones o lagunas);

6. Calderas volcánicas muy erosionadas que sirven de vasos naturales.

En conjunto, los humedales posibilitaron una región rica en nutrientes en suelo y de humedad, lo cual significó la multiplicación de la diversidad biológica en flora y fauna, comprendiendo que el área cultural que ocupaba esta región fue de "87,000 km2 y que albergaba en el Período Paquimé y Diablo 2,240 habitantes" (Weaver, 1992, p. 85).

En esta zona, se articulan diversos procesos complejos históricos-culturales-sociales-políticos-ambientales, que se traslapan, que se suman como capas o estratos que dan sentido a los paisajes culturales. Manifestándose como patrimonio cultural que le da sentido a los indicadores en el territorio estudiado. A continuación, se describen y analizan los procesos complejos que logran conformar los paisajes culturales de la región Casas Grandes-Paquimé. 
1. Patrimonio arqueológico: periodo Lítica o Paleoindio. Proceso histórico-cultural considerado como sistema de periodización que ordena las secuencias de las sociedades más antiguas del territorio mexicano basadas en criterios de carácter tecnológico observados en artefactos líticos, o de piedra, y lo hace mediante tres grandes horizontes: incluye Arqueolítico (14 000 años antes del presente), Cenolítico (entre 14000 y 7000 a. p.) y Protoneolítico (7000 y 4500 a. p.) (Márquez-Alameda, 1992, p. 107). En Chihuahua, se tienen registrados dos artefactos conocidos como Clovis y Folsom. El primero en el municipio de Ascensión "en las inmediaciones del Rancho Colorado al suroeste del poblado de Palomas y en un tributario del Río Casas Grandes" y el segundo en "un paraje denominado La Mota, en las inmediaciones de la Sierra de Samalayuca" (MárquezAlameda, 1992, p. 110). Los pobladores de estas regiones de praderas

se caracterizaron por una subsistencia basada en la caza de fauna hoy extinta y en la recolección de productos vegetales, ambos pertenecientes a un contexto climático más frío que el actual, los primeros indicadores permitieron estimar una antigüedad mayor a los 10, 400 años, ya que es hacia esta época que la fauna del periodo Pleistoceno empieza su proceso de extinción, (período) en el que hubo una serie de glaciaciones o avances y retrocesos de capas de hielo polar, entre la fauna estaba incluidos el gliptodonte, la llama fósil, el caballo americano y grandes proboscídeos como el mamut (Márquez-Alameda, 1992, pp. 108-110).

2. Periodo Prehistórico. Se desarrollaron expresiones culturales como trincheras y estrategias de conservación de suelo y agua, datadas en el periodo del Arcaico Tardío correspondiente a 3500 a. C. a 1700 d. C., que se encuentran ubicadas en el municipio de Janos, específicamente en el sitio conocido como cerro Juanaqueña. Estos paisajes naturales de pradera del noroeste de Chihuahua, se caracterizaron por utilizar geoformas sobresalientes al entorno local; así 
el sitio de interés fue construido en las cimas y pendientes de un cerro de basalto de 140 metros de altura, el cual se proyecta por encima del río Casas Grandes. Las construcciones en el área cubren ocho hectáreas incluyendo ocho kilómetros de muros de piedra apilada y de tierra y piedra compactada, así como 1000 círculos de piedra (Hard, \& Roney, 1998, p. 1).

Por otra parte, el uso de avenidas fluviales para inundar tierras para cultivo era también una práctica común. Esto último nos habla de asentamientos humanos más estables y, con ello, el desarrollo de nuevos saberes del entorno natural, por lo que desarrollar trincheras o sistemas de terraceo en cerros o lomas en la pradera significó un cambio notable en el medioambiente, posibilitando los primeros paisajes culturales del norte de México. En dichas áreas se encontraron "muestras etnobotánicas, de fauna, líticas y de polen"; del fechamiento obtenido de las muestras de maíz, mediante carbono 14, encontradas todas en el "interior de las terrazas o del relleno detrás de las paredes o vallas". Esto permite precisar que las fechas más antiguas oscilan entre 2980 a 3520 a. C.: "Los datos indican que el Cerro Juanaqueña es contemporáneo con casi todas las fechas más antiguas de plantas cultivadas en el suroeste" (Hard, \& Roney, 1998, p. 30). Es importante resaltar la presencia de cultivos, dado que se integraron nuevos elementos a la naturaleza, dándole un sentido humanizado al territorio. Se puede afirmar que, con la entrada de la agricultura, hay innovación en construcción de paisajes culturales en Chihuahua.

3. Periodo Prehispánico. En el norte de México, se empezó a cultivar maíz y calabaza como parte de su subsistencia, principalmente de pueblos nómadas de caza y recolección. No obstante, el maíz se diversificó, así como los frijoles, calabazas y chiles que en conjunto formaron un sistema agroalimentario complejo. La domesticación en América de estas plantas, es entre los años “7000 y 3000 a.C.” (Weaver, 1992, p. 62). Como consecuencia de lo anterior surgen desarrollos culturales prehispánicos que dieron a los paisajes culturales del norte de 
México y sur de Estados Unidos, nuevos elementos humanos. Hablamos de los Anasazi, Hohokam y Mogollón, que, al no existir fronteras administrativas y políticas como las contemporáneas, se diluyeron, diversificaron y combinaron variados elementos culturales, principalmente de Anasazi y Mogollón, los cuales dieron origen a la cultura prehispánica más importante del norte de México, la cultura Paquimé (véase Mapa 2). 
Mapa 2. Culturas prehistóricas de la región del noroeste de Chihuahua o región Casas Grandes-Paquimé. La zona con sombreado con líneas diagonales corresponde al área de estudio.

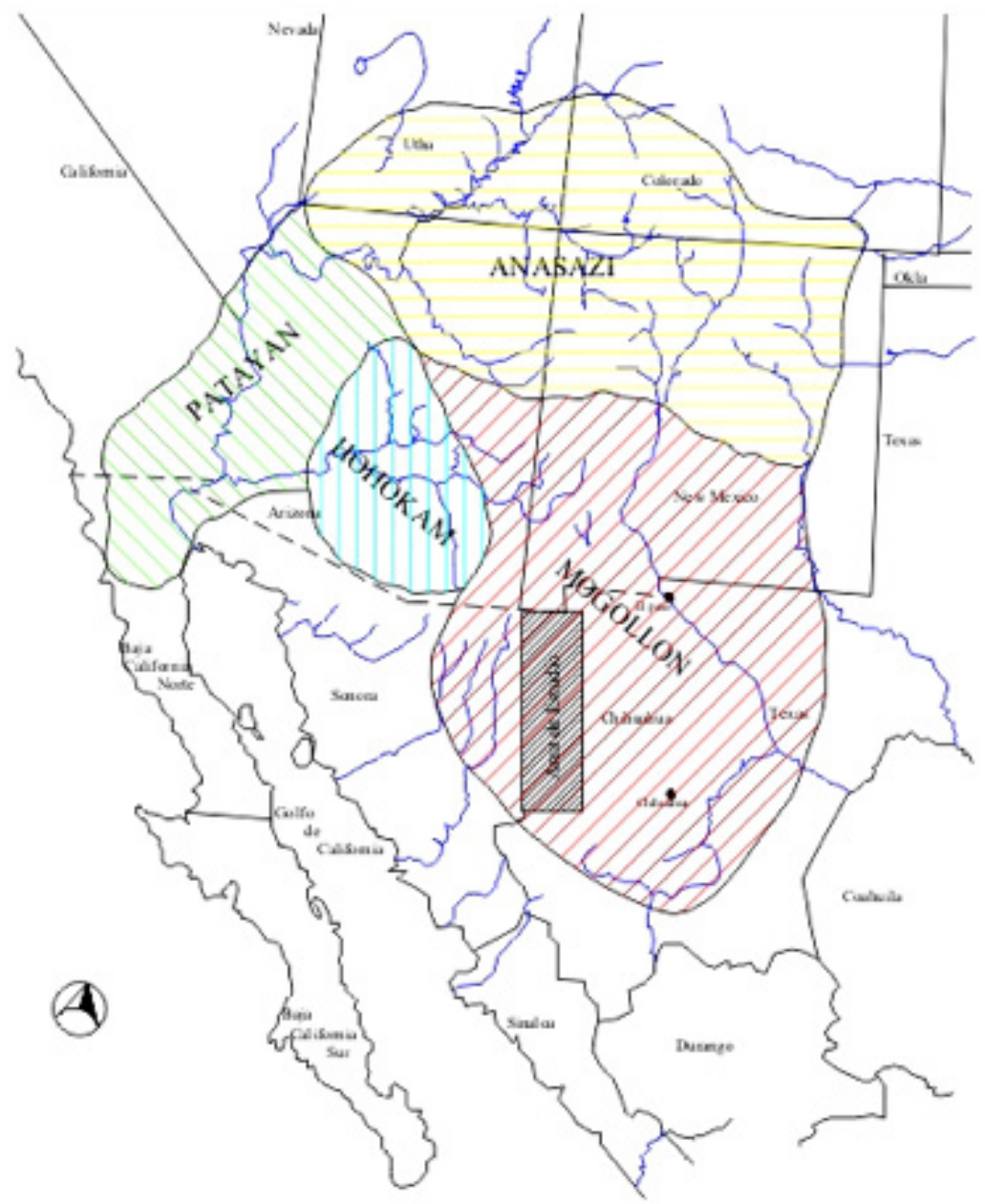

Fuente: Gamboa y Mancera-Valencia (2008).

Antes del esplendor de Paquimé existieron otros procesos culturales, que entre otras cosas muestran la conjunción cultural de los complejos Anasazi-Mogollón. El más significativo es el sitio arqueológico conocido como el "Convento" ubicado a 40 metros 
del atrio del antiguo convento colonial de San Antonio de Padua (1663-1686 d. C.), de breve existencia, "Este sitio prehistórico fue ocupado varias veces entre los años 700 y 1200 d.C., tiempo durante el cual hubo un progresivo pero modesto desarrollo. Este largo tiempo de medio siglo es conocido como el periodo viejo" (Braniff, 1997, p. 87). Estos eran aldeas constituidas por

unas diez casas: había una principal y más grande, y otras nueve pequeñas construidas del estilo de las casas-foso de planta socavada redonda, entrada lateral, muros de troncos y tierra, y techo en forma de domo también de tierra. Una segunda aldea siguió utilizando este tipo de casas.

Este sedentarismo genera mayor dependencia del agua y de la producción agrícola por la mayor demanda de alimentos. Además del maíz, frijol y calabaza, se integraron "el cultivo del algodón y del amaranto” (Braniff, 1997, p. 83); además, “sabemos que estas personas eran cazadores de conejos, antílopes y bisontes, con los cuales completaban su dieta, también quedan restos (en los sitios arqueológicos) de guajolote y guacamaya, pero esta última debió ser utilizada para ciertas ceremonias" (Braniff, 1997, p. 91). Las guacamayas eran traídas de la sierra Tarahumara, las cuales aún encuentran migraciones a lo largo de los grandes cañones y barracas (Miller, Mancera, Gringrich, \& Curiel, 1999, p. 8).

- 3a. Paquimé. Tuvo un periodo de desarrollo de 250 años (1200 a 1450 d. C.), en donde se distinguen tres regiones: Buena Fe, Paquimé y Diablo (Braniff, 1997, p. 92). Paquimé fue una ciudad que sobresalía del paisaje de pie de monte y praderas de esta región, donde su arquitectura y sistemas constructivos permitieron el desarrollo de casas de varios pisos, con áreas especiales para uso público y ceremonial situadas fuera del núcleo de viviendas. La presencia de juegos de pelota, "enterramientos bajo suelo, montículos de plataforma y de esfinge y pozos en los que 
se podían entrar" (Weaver, 1992, p. 85), para recolectar agua derivada a través de acequias.

Los sistemas hidráulicos prehispánicos, o tambien considerados sistemas de irrigación prehispánica, son fundamentales en la construcción de los paisajes culturales de esta zona. Específicamente por los siguientes motivos: i) Infraestructura hidráulica prehispánica notable en la superficie, dejando claras acciones antrópicas sobre el territorio; ii) Sistemas constructivos de los sistemas hidráulicos prehispánicos (piedra, adobe y cal), que permiten la permeabilidad de la humedad, logrando el desarrollo de vegetación arbórea y de avifauna vinculada a bosques de galería.

Especialmente en la región Casas Grandes-Paquimé (véase Mapa 3), podemos encontrar los siguientes sistemas de irrigación prehispánicos (Mancera-Valencia, 2016):

d) Sistemas de irrigación, a través de canales de gran longitud y conducción de agua fluvial, de manantiales y de agua superficial de origen pluvial, practicados en la región de Paquimé (Di Peso et al., 1974; Braniff, 2000; Doolittle, 2004).

e) Sistemas de manejo de excedentes hídricos (vertederos y compuertas) en la ciudad de Paquimé (Braniff, 2000).

f) Sistemas de vertederos de control de aguas torrenciales fluviales o pluviales (Braniff, 2000; Doolittle, 2004).

g) Sistemas de abasto de agua domestica, a través de canales cubiertos y sistemas de acequias (Braniff, 2000; Doolittle, 2004).

h) Sistemas de decantación, aljibes y pozos (Braniff, 2000). 
Mapa 3. Región cultural Casas Grandes-Paquimé. Paisajes culturales prehispánicos

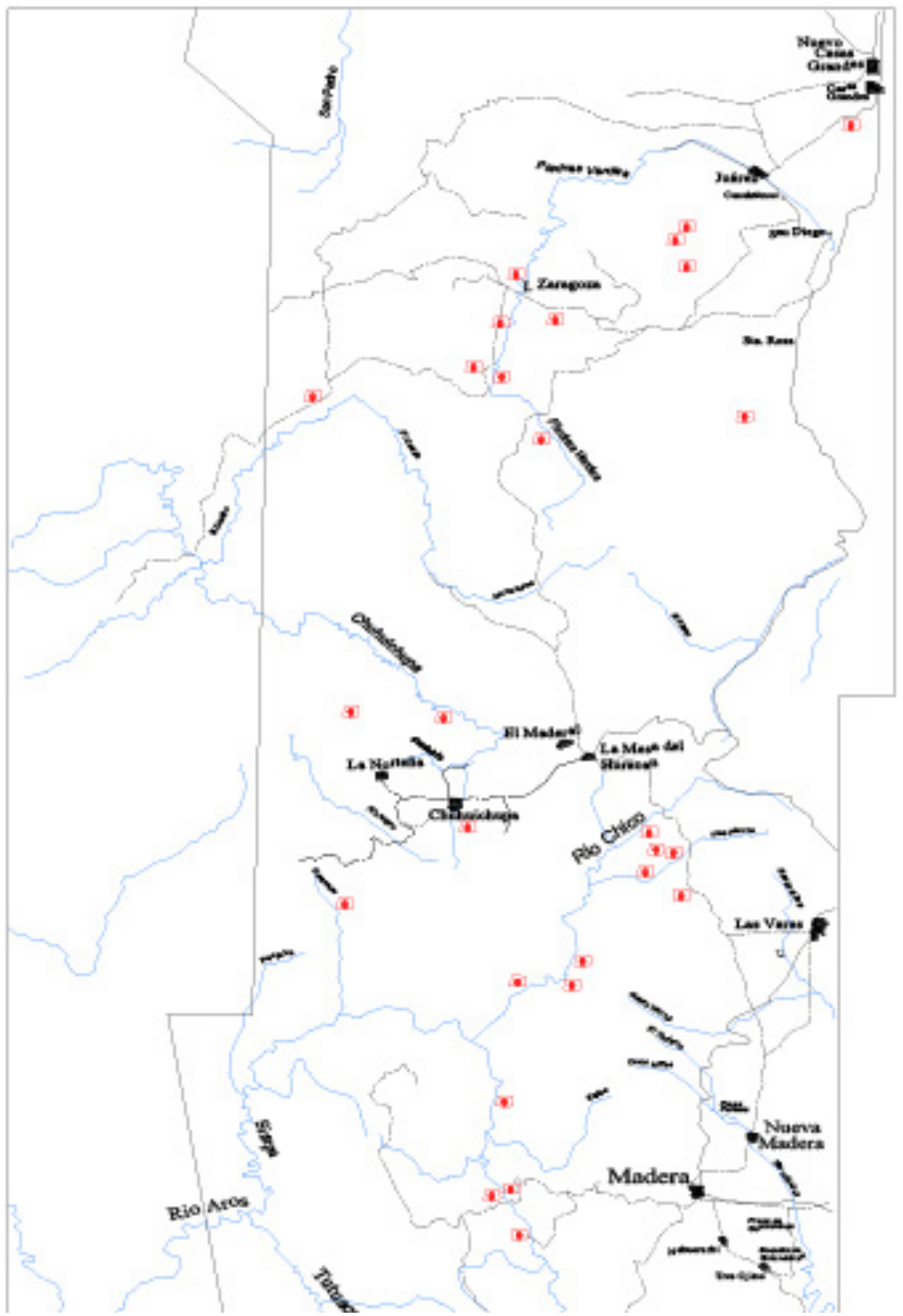

Fuente: Gamboa-Mancera Valencia (2008). 
En Paquimé y en su región, los sistemas de abastecimiento y control del agua aún son notables. Un manantial de aguas termales localizado a $4 \mathrm{~km}$ al norte de Paquimé, conocido actualmente como Ojo Valereño, surtía de agua a dicho sistema. Se han identificado varias acequias que en conjunto suman más de $5 \mathrm{~km}$ de acequias (Foster, 1992, p. 258) y poseían dos presas en cada una de ellas: "era circular y sus diámetros tenía 22 m., y una profundidad de 3,5 m, el agua estaba primero a un filtro, pues ahí se depositaban los sedimentos". También "desarrollaron un sistema de drenaje de plazas concentrado a cisternas, que sin duda funcionaron para el desagüe de la ciudad durante las lluvias, (...), las líneas de esos drenes eran de piedras alineadas y cubiertas con lajas". De igual manera, es interesante el sistema de alcantarillado, "los análisis químicos de los suelos de esas zanjas indican que fueron usadas para sacar desperdicios humanos de los edificios. No están claras las consecuencias que pudieran acarrear a la salud humana esos desagües", hecho que manifiesta también los posibles problemas de "contaminación" en la ciudad.

La sistematización de conocimientos y saberes del entorno natural, se ve reflejada en el desarrollo de estas tecnologías. Para estas zonas de pie de monte, ubicadas en el semidesierto chihuahuense, los saberes y conocimientos bioculturales resultan fundamentales para la producción: para el caso de selección de semillas apropiadas para cierto tipo de condiciones climáticas, de los ciclos hídricos regionales, conocimiento de los suelos, policultivos para aprovechar las diferencias locales microecológicas en cuanto a los efectos del viento, humedad, tipo de microorganismos, ciclos vegetativos y de fauna, entre otros.

- 3b. Casas Grandes o sitios con casas acantilado. Están ubicados al noroeste de la sierra Madre Occidental. Se desarrollan en valles intermontanos, llanuras de pie de monte y valles extensos. En esta zona se desarrolló un sistema de conservación de suelos y de agua superficial muy importante, el cual puede considerarse como parte del conjunto 
de sistemas de irrigación prehispánica en bosques templados secos.

El sistema estaba compuesto de "bordes lineales de 6 a 150 m. de longitud siguiendo patrones de los arroyos", con el fin de conservar el suelo en pendientes pronunciadas. También había terrazas construidas en las laderas de pendientes fuertes, "[las] cuales varían de 6 a $70 \mathrm{~m}$. Su función es incidir en la disminución de torrente, de tal modo que permite la creación de un manto residual por deslave del suelo"; asimismo, se identificaron trincheras, trincheras laterales, bordos, canales, acequias y norias (Gamboa, 2001, p. 1).

Este sistema de trincheras, terrazas y bordos, se han ubicado en esta extensa región de paisajes culturales, tanto en el cerro de Trincheras, en Janos, como en la zona montañosa de Cuarenta Casas en los sitios de Sírupa, Huápoca y Cañón del Embudo, así como en el sistema de barrancas de la sierra Tarahumara (Di Peso et al., 1974; Gamboa y Mancera-Valencia, 2008; Braniff, 2000; Guevara, 1986).

En la zona de paisajes culturales de Casas Grandes, caracterizados por las casas acantilado y los sistemas de irrigación prehispánica de montaña, se puede observar lo siguiente (véase Mapa 3):

1. Los sitios de la montaña están estrechamente ligados al sistema regional donde Paquimé fungió como la ciudad ritual real. Los elementos iconográficos encontrados durante nuestro reconocimiento arqueológico de superficie coinciden fielmente con la tradición de los cultos de la serpiente emplumada y de la guacamaya (Gamboa, \& Mancera-Valencia, 2008).

2. Existe un sistema de comunicaciones a través de atalayas y caminos que lo integran regionalmente, permitiendo así la apropiación sociocultural del territorio (Gamboa, \& ManceraValencia, 2008).

3. Todos los sitios arqueológicos registrados del tipo casas acantilado responden a un patrón de tipologías arquitectónicas se- 
mejantes entre sí y al empleado en la ciudad arqueológica de Paquimé. Las instalaciones y acabados arquitectónicos guardan las mismas proporciones que los sistemas constructivos de Paquimé. Nos referimos tanto a los materiales como a los sistemas constructivos; al diseño de puertas, plantas arquitectónicas, pasillos, plazas, niveles de construcción, así como a los usos y funciones de dichos espacios en pequeña escala (Gamboa, \& Mancera-Valencia, 2008).

4. Los datos sugieren una ocupación que se remonta a los orígenes de todo el sistema regional de Casas Grandes, basado en la apropiación de la naturaleza, así como de los recursos naturales básicos, como es el caso del agua y el suelo, a partir de la tecnología de la trinchera, en áreas de transición ecológica de bosques de encino y encino-pino, y bosques mixtos, mostrando así una compleja articulación entre cultura y naturaleza (Gamboa, \& Mancera-Valencia, 2008).

5. Paralela a la conclusión anterior, la construcción espacial de su territorio está basada de igual manera en la satisfacción de su sistema de necesidades ambientales, creencias, rituales, fiestas y lenguaje, entre otros elementos (Gamboa, \& Mancera-Valencia, 2008).

6. La existencia de facilidades como graneros para el almacenamiento de la producción agrícola, nos habla de una organización socioeconómica basada en el centralismo y la redistribución, que permite no solo el control productivo a través del tiempo sino también a través del lugar, es decir, del control espacial del uso y manejo de los recursos naturales (Gamboa, \& Mancera-Valencia, 2008).

7. El sistema regional de Casas Grandes es un paisaje cultural complejo, donde los indicadores se suman para dar sentido a una zona geocultural específica de la sierra Madre Occidental.

8. Múltiples saberes y conocimientos bioculturales de la región, se heredaron a los pueblos indígenas de la sierra Tarahumara, como la práctica de trincheras, sistemas de captación de agua pluvial, manejo diversificado de los recursos de flora y fauna, etcétera. 
Con el sedentarismo gestado en el área de Casas GrandesPaquimé, se desarrollaron nuevas y mayores necesidades, y, con ello, la consolidación del comercio de diversos productos, articulándose así otras regiones, generando una división socioespacial del trabajo y de las clases sociales, grupos y zonas productivas especializadas, desenvolviendo nuevas vías de comunicación, entre otros procesos.

4. Colonia y Virreinato. Con el desarrollo de los agroecosistemas en la región Casas Grandes-Paquimé, se intensificaron los usos de los distintos elementos de los ecosistemas diversificando el uso del territorio y, con ello, se complejizaron las relaciones de la cultura-naturaleza. Estas transformaciones de los ecosistemas y del territorio de las culturas prehispánicas fueron reutilizadas por la gente de la Colonia y del Virreinato español. Es el caso de los sistemas hidráulicos prehispánicos, ya que se fortalecieron y reutilizaron con las tecnologías constructivas de los españoles y su herencia árabe al-Ándalus, incluyendo nuevos usos de materiales, como la cantería, mampostería de piedra, aplanados y sistemas de ligamento con cal y grava, que fueron base de las construcciones de casas-habitación, templos de misión y presidios en toda la región.

Así, las estrategias geopolíticas de las misiones y presidios, junto con las formas de control militar y económico de la población local, a través de las encomiendas y repartimientos, posibilitaron el desarrollo del poblamiento y ocupación del territorio, por lo menos mientras se controlaban las rebeliones de los pueblos originarios.

Por lo anterior, es importante considerar el área geocultural como gran concentradora de patrimonio cultural prehispánico, colonial y virreinal, pues estos procesos históricos-culturales-sociales-políticos-ambientales constituyeron la amalgama para dar sentido a los paisajes culturales de esta zona. A los ojos de estudiosos del paisaje, se ven dispersos lo elementos culturales que lo componen, pero esta es la forma geocultural en la que los paisajes culturales del septentrión se manifiestan en el territorio. 
Hoy, a 2019, los paisajes culturales de origen colonial y virreinal, de la región Casas Grandes-Paquimé pueden ser comprendidos y observados como islas intercontinentales rodeadas de extensas y prolongadas llanuras con pastos, con sucesión vegetativa de plantas arbustivas y xerófitas, interrumpidos por escurrimientos superficiales perennes con humedales dispersos; ahí se localizan en los ranchos aislados, en centros de población rural-urbano, entornos rurales con paisajes agrícolas, pecuarios y agroforestales. Las condiciones de semidesierto y de sequías hacen que la necesidad del agua para uso humano, principalmente ganadero, sea el motivo de cambios en el paisaje para esta época específica del año, generando un potenciador creativo de renovados sistemas hidráulicos aun sobrevivientes del mundo prehispánico (véase Mapa 4).

5. Independencia al Porfiriato. Son casi doscientos años en los que los paisajes culturales de esta zona Casas Grandes-Paquimé, se mantuvieron "dilatadamente estables". En el periodo independiente, se usaron las llanuras extensas con pastizales para la actividad ganadera, lo que trajo consigo grandes latifundios y el desarrollo de centros de población criolla y mestiza. No obstante, poblar este territorio fue de gran dificultad. Durante todo el siglo XVII hasta finales del XIX, se hizo posible de forma continua la ocupación del territorio del septentrión mexicano:

Fomentar el poblamiento sedentario (agrícola) era una estrategia distinta al belicismo con que algunos sectores del gobierno colonial (español) intentaron remediar el carácter insumiso y rebelde de los indígenas del Septentrión [...]. El proyecto de la Comandancia General de las Provincias internas contemplaba un amplio esfuerzo de expansión del dominio español en el septentrión, en el cual destacaba la necesidad de fomentar el poblamiento a través del desarrollo de la minería, la fundación de poblados que gozarían de privilegios diversos, la apertura de nuevas comunicaciones y la mejoría en los sistemas de presidios [...]. La preocupación colonia se hereda [...] al país que nació en 1821. A partir de entonces y durante poco más de 
un siglo, reforzar la ocupación efectiva del territorio constituyó una de las principales preocupaciones de los gobiernos nacionales. Este problema estaba profundamente vinculado al poblamiento del país [...]. No sólo tenía que ver con el escaso número de habitantes y su deficiente distribución en las distintas partes del territorio [...]. El poblamiento precario se traducía en una amenaza constante de pérdida territorial [...] lo que es una necesidad inherente de todo Estado moderno de conformar y reivindicar su territorio frente amenazas externas e internas (Aboites, 1995, pp. 22-23).

Los procesos de cambio, tanto internos como externos o combinados, en el sentido geohistórico que se manifestaron en este territorio, más que amenazas fueron oportunidades de colonización. En primer lugar, de tipo externo, que generaron los conflictos con los norteamericanos y la consecuente pérdida de territorio mexicano en 1848. 
Mapa 4. Situación del uso de suelo y vegetación: sustento de los paisajes culturales de la región del noroeste o Casas Grandes-Paquimé

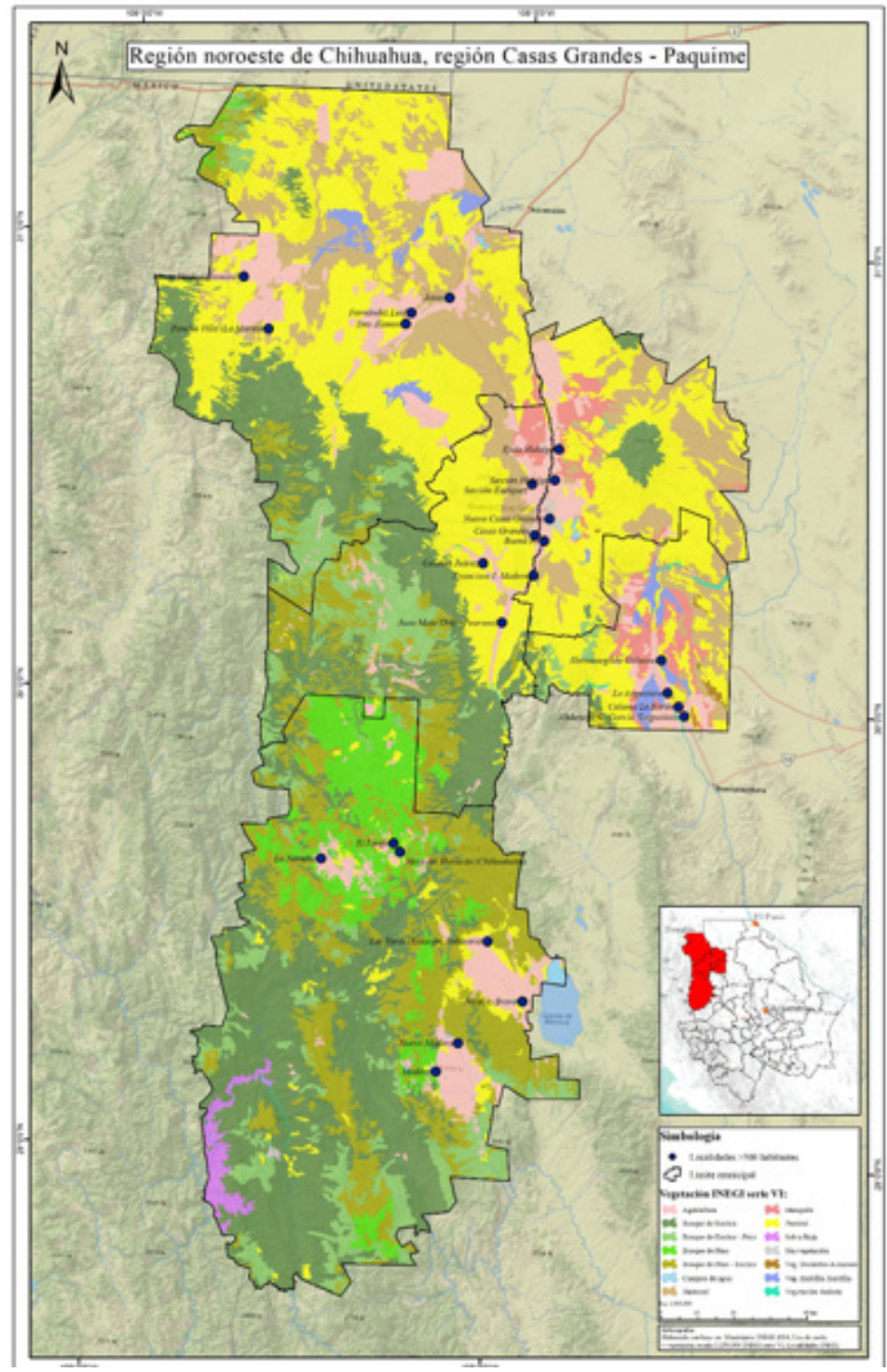

Fuente: elaboración propia con base en el Inegi (2014). 
En segundo lugar, de tipo interno-externo. La zona se constituyó como área de refugio de las culturas nómadas de apaches y comanches, ya que transitaban de manera natural y constante por esta región geocultural. Estos lograron contener la expansión de la ganadería y la minería como parte de la modernidad criolla y mestiza. En tercer lugar, de tipo externo, con la migración de mormones (siglo xIX) y menonitas (siglo xx), que lograron modificar esta área tanto en términos geográfico-económicos como en la condición de los paisajes. Por último, de tipo interno con intereses externos, debido a que la construcción del ferrocarril permitió la división territorial y el flujo productivo geoeconómico, lo que facilitó la definición de latifundios y la extracción de diversos recursos naturales, como el forestal. El conjunto de estos procesos contribuyó a la "dilatada estabilidad" o cambio contundente de los paisajes culturales de la región Casas Grandes-Paquimé.

- 5a. Nómadas apaches. Los pueblos nómadas atapascanos, como los apaches, dejaron elementos culturales materiales en los sitios arqueológicos de la cultura Casas GrandesPaquimé. Al respecto, Víctor Orozco (1997) cita un informe fechado el 27 de marzo de 1871, que fue elaborado por expediciones contra apaches:

se menciona el descubrimiento en la sierra de Chuichupa, una cueva que en su interior tenía 60 casas Se trata probablemente de las ruinas arqueológicas de "cuarentas casas" que pertenecen a la cultura Paquimé [...] indica que hallaron viviendas en una cueva que tenia de largo al menos 500 varas y dentro 60 casas y en ellas tallas de maíz. Los restos de maíz revelan que los apaches conocían estas ruinas y ocasionalmente las habitaban (Orozco, 1997, p. 140).

Por otra parte, estos pueblos dejaron su cosmovisión a través del arte rupestre en abrigos rocosos, o bien, en bloques o frentes rocosos separados o disgregados, tanto en las superficies como en las paredes en cuevas. Los pueblos nómadas, apaches y comanches, tienen 
una visión dinámica relacionada con sus trashumancia o movimiento continuo [...] y que se reproduce al buscar el alimento a través de la recolección de plantas, la cacería de animales y la pesca, así como por conseguir agua; por lo tanto, la expresión gráfica de los cazadores-recolectores-pescadores es de carácter lineal y se ordenó bajo patrones de repetición (Mendiola, 2008, p. 12).

También dejaron morteros fijos a lo largo de sus rutas e itinerancias, así como utensilios en las casas acantilado de la región de Casas Grandes, y sitios de observación en los parteaguas de las sierras y cerros de la zona, hasta que fueron exterminados y expulsados a fínales del siglo XIX, por parte del entonces gobierno de Chihuahua. Esta cultura dejó su marca en la narrativa del paisaje cultural de la región.

- 5b. Deslinde y colonización del territorio del noroeste: la migración mormona. Múltiples procesos geohistóricos son los que hay que considerar para la comprensión de los paisajes culturales que se observan hoy en la zona de Casas Grandes-Paquimé. Como he tratado de explicar, los paisajes culturales son la suma de múltiples procesos, entre ellos, los jurídicos que impactan en el territorio.

Durante el gobierno de Porfirio Díaz, los ordenamientos jurídicos de orden federal fueron de dos tipos: el Decreto sobre Colonización y Compañías Deslindadoras, del 15 de diciembre de 1883, y la Ley sobre Ocupación y Enajenación de Terrenos Baldíos, del 25 de marzo de 1894. Estas leyes permitían identificar tierras que carecían de propietarios para incorporarlas a la vida económica del país, a través de su deslinde y mediación, y con ello la venta a particulares. En dichas leyes, las compañías deslindadoras asumieron la responsabilidad de localizar terrenos baldíos, deslindarlos, medirlos y de transportar hasta ellos a los colonos que debían trabajarlos una vez que estuvieran fraccionados (Guerrero, 2016, p. 2).

Así se estimula la ocupación territorial del gobierno porfirista y todavía hasta la década de 1930, se mantuvo, no desde la forma de 
las compañías deslindadoras, pero sí del papel del gobierno mexicano de recibir inmigrantes extranjeros: mormones y menonitas, y de otorgarles territorio.

En 1885, un grupo de 400 Santos de los Últimos Días (SuD) o mormones viaja a México con fines de colonizar nuevos terrenos. Son estimulados por: 1) Las reformas liberales de Benito Juárez García; 2) La necesidad del gobierno republicano de México de poblar el septentrión; y 3) Hacer "productivo el desierto". Después de diez años, obtuvieron territorios en el área de Casas Grandes, donde se fundaron las siguientes colonias: Colonia Juárez, Dublán, Díaz, Pacheco, García y Chuhuichupa (véase Mapa 1).

Las colonias fundadas en la región de Casas Grandes-Paquimé, se encontraron dispersas en el territorio; no obstante, se fueron consolidando económicamente a través del intercambio de bienes, productos y materiales que cada colonia, de acuerdo con su entorno medioambiental, era capaz de producir. Por ejemplo, en las zonas de planicies con pastos y llanuras aluviales, se gestó la irrigación, en donde reutilizaron canales prehispánicos, como el de la rivera del río Piedras Verdes, por lo que florecieron los cultivos y la industria enlatadora en Colonia Juárez: "enlataban su abundante cosecha de huertas y jitomates. Un año más tarde esa fábrica, dirigida por Joseph C. Bentley, un empresario quien más tarde figuró prominentemente en la historia de las colonias producía diez mil latas" (LaMond, 2012).

Por su parte, en Cave Valley, Pacheco, García y Chuhuichupa, que eran colonias ubicadas en la sierra, posibilitaron el desarrollo de aserraderos y productos derivados de la madera. También utilizaron las áreas de las mesas y praderas intermontanas para el pastoreo. Así, la industria forestal y ganadera se potenció regionalmente.

Entre los sud que llegaron a México:

Había granjeros, horticultores, hombres de negocios, maestros y médicos, todos ellos con mucha experiencia [...]. Miles P. Romney era historiador reconocido [...] y estudioso de las campañas militares de Napoleón Bonaparte y Alejandro Magno [...]. A los cincuenta y cua- 
tro días de su arribo a Juárez, los colonizadores ya habían construido un lugar que funcionaba como escuela en la que la esposa de Romney enseñaba; y antes de que éste quedara terminado, ya trabajaba con ellos en su refugio subterráneo. Muchos de estos hermanos ya eran líderes experimentados de la Iglesia (LaMond, 2012).

Se puede afirmar que el impacto migrante mormón, contribuyó en mucho a la modificación y diversificación de los paisajes culturales de la región de Casas Grandes-Paquimé, ya que se integraron nuevos elementos edificados (LaMond, 2012) que modificaron el territorio y los paisajes culturales previos:
a) Construir sistemas de irrigación;
b) Plantar árboles frutales con la esperanza de cosechar en cinco años;
c) Planear comunidades;
d) Organizar y operar escuelas;
e) Construir capillas;
f) Establecer aserraderos;
g) Producir energía con agua;
h) Atender asuntos espirituales;
i) Crear hospitales;
j) Crear panteones;
k) Plantar, cosechar, almacenar y desarrollar comercio con los mexicanos; y
l) Construir molinos, curtidurías, plantas procesadoras de co- mida, talabarterías, herrerías y tiendas.

En realidad, se crearon paisajes culturales mormones, lo cual responde a una estrategia de organización geográfica o territorial y educativa. El 9 de diciembre de 1895, se crea la primera "estaca" en territorio mexicano. "Estaca" es una noción geopedagógica, ya que al integrar un conjunto o "grupo de barrios", se forma una estaca y el líder de esta, se convierte en su presidente.

El término no se encuentra en el Nuevo Testamento, pero se toma de la representación de una tienda del Antiguo Testamento 
en la cual la tienda o la iglesia es sostenida por estacas de apoyo. Los barrios o ramas son congregaciones mormonas pequeñas. Los miembros asisten a un barrio o a una rama cerca de sus domicilios.

La Iglesia de Jesucristo de los Santos de los Últimos Días pedagógicamente emplea los mismos materiales de enseñanza en todos los barrios y las ramas, de tal forma que una persona estará cursando las mismas lecciones sin importar en qué parte del mundo asistan a la iglesia. El líder espiritual de cada barrio es el obispo o presidente de rama. La estaca sud en Chihuahua es la número 37 en general y se crea con la característica de ser en inglés y español; dicho modelo bilingüe permanece hasta la actualidad.

Las actividades geoeconómicas principales de los SUD en la región son: agricultura, horticultura, ganadería y avicultura. Son singulares la cría de pavos Parson y los huertos de duraznos, encontrándose entre los mejores del país. Las huertas de duraznos son una práctica que se diseminó regionalmente por esta cultura migrante.

Simultáneamente, en el Porfiriato se consolidan las oligarquías regionales, ya que aprovechan los ordenamientos federales consolidando sus latifundios; por ello, se reutilizan nuevamente las llanuras con pastizales y también las llanuras aluviales, donde se reestablecieron y reconstruyeron nuevos sistemas de riego para alimentar y mantener las haciendas, como el caso de las propiedades del general Luis Terrazas. "Las haciendas de Luis Terrazas [...] sumaban 17, las cuales fueron manejadas en tres grupos [...]; un grupo era las que estaban situadas en los municipios de Casas Grandes, Galeana y Buenaventura” (Hernández, 2016, p. 25).

Las fincas que se gestaron en este territorio tan extenso fueron: El Carmen y Anexos, San Isidro, Las Varas, Ojo Caliente, San Diego, Tapiecitas y Anexo, San Lorenzo y Anexos, San Luis y Anexos y la Cristabeleña. En total sumaban, solo para esta zona, 890633 ha. ${ }^{9}$ (Hernández, 2016, p. 25). Buena parte del territorio de estas fincas era atravesado por el ferrocarril, el cual dejó al tiem-

9 Archivo Particular de la familia Muñoz (10 de agosto de 1921). Inventarios Luis Terrazas y Doña Carolina Cuitly de Terrazas (Hernández, 2016, p. 25). 
po patrimonios edificados como cascos de haciendas, conjuntos arquitectónicos hacendarios, estaciones de ferrocarril ubicadas en las fincas de Terrazas, que en su momento facilitó el transporte del ganado y de la madera extraída de la sierra Tarahumara, así como de múltiples productos agropecuarios.

En 1909, el ingeniero Frederick Stark Pearson proporcionó la "Estación Pearson", lugar en que terminaban las líneas del ferrocarril. Después de la Revolución mexicana, en 1925, por decreto del H. Congreso del Estado, "Estación Pearson" se convertiría en el poblado de "Juan Mata Ortiz”. Esta estación ferrocarrilera permitió el transporte de madera extraída de la sierra de Casas Grandes y de Mesa del Huracán, del municipio de Madera, la cual era aserrada en maquinaria propiedad del ingeniero Pearson. El diseño arquitectónico de esta estación es singular con una gran estética que sobresale en la región.

- 5c. El Ferrocarril del Noroeste, que se conecta al Ferrocarril Central, fue iniciado en 1909, a través de la concesión otorgada por la Secretaría de Comunicaciones y Obras Públicas el 22 de noviembre a la compañía del Ferrocarril del Noroeste. ${ }^{10}$ Fue autorizada para construir un tramo de Nuevo Casas Grandes al pueblo de Madera "a fin de ligar las antiguas vías de ferrocarriles Río Grande, Sierra Madre, Pacífico y de Chihuahua al Pacífico, y establecer la comunicación directa entre Chihuahua y Ciudad Juárez, a través de la Sierra Madre Occidental" (Almada, 1971, p. 156).

Los intereses extranjeros estimulados por los ordenamientos federales contribuyeron a la búsqueda del control y posesión de este extenso territorio. Es el caso del dueño de las minas de Cananea, coronel William C. Green (Burgues, \& Burgues, 2014, p. 48), quien a su vez tenía la concesión del Ferrocarril ChihuahuaPacífico y Sierra Madre (Almada, 1971, p. 147); el senador nortea-

10 Francisco R. Almada (1971) dice que el licenciado Luis Riba fue quien inició este convenio; además, menciona que el contrato de construcción fue para el ingeniero W. A. Bird (pp. 100-101). 
mericano George Hearts, padre de William Randolf Hearts, dueño del latifundio de la hacienda de Bavícora, cuya propiedad fue adquirida con apoyo del general Porfirio Díaz en 1882 (Wasserman, 1987, p. 182; Burgues, \& Burgues, 2014, p. 48) y, además, el "ingeniero electricista y empresario Frederick Stark Pearson, quien era propietario de un gran aserradero en esta región" (Burgues, \& Burgues, 2014, p. 48) (véase Mapa 1).

El aserradero se ubicó en la Estación Pearson, hoy Mata Ortiz. La estación es considerada patrimonio edificado y catalogado por registros del Centro INAH-Chihuahua. El tramo de Casas Grandes y esta estación se inauguró en julio del 1910. El tramo concluido Mata Ortiz-Madera, se terminó en octubre de 2011, así como el que llegaría a Ciudad Juárez. La longitud del ferrocarril desde Chihuahua hasta Ciudad Juárez vía ruta noroeste, es de 759 km (Almada, 1971, p. 157). El transporte público del ferrocarril tuvo viajes diarios de Chihuahua-Madera y Ciudad Juárez-Madera, a los que se sumaban los ramales La Junta-Miñaca y CuauhtémocCusihuiriachi.

El Ferrocarril del Noroeste atraviesa este territorio otorgando al paisaje un sentido apropiación espacial y de división territorial, que, al mismo tiempo, permite la articulación de dispersas poblaciones urbanas y rurales (islas intracontinentales) con las extensas llanuras, posibilitando una continuidad de comunicación, de ocupación poblacional entre la región central del estado y el noroeste, así como el desarrollo comercial local-regional de ganado y madera, y con ello, la extracción forestal (véase Mapas 1 y 4).

Con los decretos sobre Colonización y Compañías Deslindadoras (1883) y la Ley sobre Ocupación y Enajenación de Terrenos Baldíos (1894), se viabilizó la extracción y explotación forestal regional. La Compañía del Ferrocarril Noroeste de México consolidó un enorme latifundio de 1047700 ha de montaña con bosques templados secos en los distritos judiciales de Galeana y Guerrero, debido a que adquirió todos los terrenos que habían pertenecido al coronel Green y otras facciones provenientes de las compañías deslindadoras que habían trabajado en todo el estado de Chihuahua (Almada, 1971, p. 158). 
La empresa The Madera Company Limited fue una subsidiaria de la Compañía del Ferrocarril Noroeste de México, quien con la autorización del gobernador Enrique C. Creel, en abril de 1910, se convirtió en la principal empresa deslindadora, con exención de impuestos, en el septentrión mexicano. Esta empresa intensificó la explotación forestal que había iniciado Green en Madera y, posteriormente, la Compañía del Ferrocarril Noroeste de México en Casas Grandes y Mata Ortiz, y más lugares colindantes, y más allá como era común, a la vía férrea. Esta actividad de devastación, como afirma Francisco R. Almada, fue sistemática a partir de 1917 cuando se expidió la Constitución Federal (Almada, 1971, p. 159):

Afirmo que dicha explotación forestal se hizo a base de devastación porque los pinos que no entraban a los serruchos, se hacían leña para distribuirla en las principales poblaciones chihuahuenses, en las cocinas de los millares de trabajadores que empleaban en sus obras e instalaciones y para alimentar las locomotoras de los ferrocarriles locales, que en su totalidad empleaban esta clase de combustible. No fue hasta que en 1935 cunad la Sría. De Fomento dictó las primeras disposiciones para la explotación de nuestros bosques se verifique de una manera ordenada y razonable (Almada, 1971, p. 159).

Esta explotación forestal trajo consigo diversos cambios: en el ambiental, modificaciones en los flujos y balances hídricos regionales de la montaña, y de las vertientes del Pacífico y semidesierto; igualmente, se intensificaron los procesos erosivos provocando desertificación en la montaña como en los desiertos y semidesiertos, desaparición de especies endémicas, contaminación de suelos por materiales residuales de los ferrocarriles y aserraderos; en la cuestión social, migraciones internas de la montaña al semidesierto; se generó dependencia económica y tecnológica de la producción forestal, entre otras cosas.

6. Posrevolución. De 1921 en adelante, las actividades primarias, vinculadas al uso directo de los ecosistemas del semidesierto y de los bosques templados, son las dominantes para el de- 
sarrollo de los paisajes culturales de la zona Casas GrandesPaquimé, centrándose en la ganadería extensiva y en actividades agrícolas, frutícolas y hortícolas que se desarrollan en función del mercado internacional por la población local y, asimismo, de los inmigrantes que fueron insertando sus procesos productivos al paisaje, que además de los sud, se suman a esta región los menonitas.

- 6a. Los menonitas. Llegan a México en 1921 y su peregrinaje es largo y con distintos acontecimientos y procesos. $\mathrm{Su}$ presencia se inicia con las gestiones de menonitas Altkolonier del área de Hague-Osler, Saskatchewan, Canadá, quienes habían realizado contacto con el empresario Arturo J. Braniff, cuñado del presidente Álvaro Obregón, sobre la posibilidad de poder adquirir terrenos y un privilegium en México, que es una serie de acuerdos menonitas que se establecen en los gobiernos donde buscaban asentarse, en el que se incluye la libertad para practicar su religión, la exención del servicio militar, así como el derecho de tener sus propias escuelas en las que el alemán fuera el idioma de enseñanza (Taylor, 2005, pp. 6, 13).

Aun impulsado por la experiencia de los ordenamientos federales con los mormones, el menonita y reverendo Julius Wiebe, en septiembre de 1920, conoce a Braniff, quien encabezaba una de las compañías colonizadoras reconocidas oficialmente por la Secretaría de Agricultura y Fomento. De forma paralela, Braniff envía una carta a la Secretaría de Relaciones Exteriores de México explicando los motivos menonitas al querer inmigrar a México, así como los beneficios que podrían aportar al país. El 17 de febrero de 1921, un comité menonita, el secretario de Agricultura, Antonio I. Villarreal, y Braniff, se entrevistan con el general Álvaro Obregón, para plantear sus motivos para inmigrar a México, así como la posibilidad del otorgamiento de un privilegium (Taylor, 2005, pp. 6, 13). 
El 25 de febrero de 1921, el presidente consintió en otorgar a los Altkolonier el privilegium, que constituía las siguientes condiciones: 1) Exención del servicio militar; 2) Liberación de cualquier juramento; 3) Libertad religiosa; 4) Libertad para establecer sus propias escuelas con sus propios maestros; 5) Libertad para administrar sus propiedades según sus propios criterios, así como para establecer sus propios reglamentos al respecto. Este último es el que modificó el paisaje de los semidesiertos de Chihuahua. Gran parte de los territorios otorgados a los menonitas Altkolonier fue en los terrenos del latifundio de la hacienda Bustillos de Luis Terrazas, en lo que fueron las inmediaciones del rancho San Antonio de los Arenales, hoy ciudad Cuauhtémoc.

Este fue un momento de gran iniciativa de atracción de inmigrantes europeos por parte del gobierno obregonista. Luis Aboites realiza un importante análisis al respecto (1995, pp. 150-154). Específicamente resaltamos una nota periodística que recupera del 21 de marzo de 1921 del diario Excélsior, donde se informa que la Secretaría de Agricultura subvenciona

a los inmigrantes extranjeros, con el importe íntegro de su pasaje dentro de la república [...], que se les proporcione un 50\% del costo del transporte de bultos y muebles de su uso personal, de los implementos de agricultura que consigo traigan y de los animales de cría o para servicios agrícolas que posean y se les dé el importe íntegro de los derechos aduanales que deban pagar los mismos (Aboites, 1995, p. 154).

En 1959, de ciudad Cuauhtémoc salió un grupo de familias para asentarse en la región de Casas Grandes, al noroeste de dicha entidad; ahí fundaron la colonia Buenos Aires; posteriormente se fundaron otras colonias en otros municipios de la zona geocultural estudiada; en Ascensión: El Sabinal, El Camello, La Salada y La Sombra; en Buenaventura, El Valle, Pestañas, El Llano, Cerro Blanco, Vado de Santa María; en Janos: Buenos Aires, El Cuervo, Las Virginias, Buenavista; y en Nuevo Casas Grandes, El Capulín, 
sumando aproximadamente, para 2010, siete mil menonitas (Bautista, \& Sánchez Carlos, 2018, p. 752) (véase Mapa 1).

Para 2019, en estos asentamientos, debido a la autorización del cambio de uso de suelo del ecosistema de pastizal a las actividades de agricultura de riego, los menonitas desmontan grandes extensiones de pastizales. Además de la extracción de agua subterránea y el sobreúso del suelo, la utilización de agroquímicos causa el efecto de desertificación. Cuando se agota el agua subterránea, se trasladan a otra área y solicitan con éxito el cambio de uso de suelo, provocando un agotamiento de los acuíferos y una seria fragmentación del hábitat del desierto chihuahuense (Pool, Panjabi, Macías-Duarte, \& Solhjem, 2014; De la Maza, Banda, Mendoza, Leal, \& Rendón, 2019).

Los paisajes culturales de las llanuras con pastizales del semidesierto chihuahuense ofrecen servicios ecosistémicos singulares:

i. Participan en la captura de carbono atmosférico para su conversión en biomasa (De la Maza et al., 2019; Macías-Duarte, Panjabi, \& Aguirre, 2016).

ii. Constituyen uno de los ecosistemas pastoriles más adecuados para dar sustento a los animales herbívoros domésticos, que a su vez sirven para el consumo humano (De la Maza et al., 2019).

iii. Proveen hábitats que constituyen zonas de alimentación, reproducción o descanso para diversas especies: invertebrados; aves (rapaces como águila real, halcón aplomado, búho cuerno corto, aguililla de Swainson, tecolote llanero; aves semilleras insectívoras); mamíferos (rata canguro, tuza, perrito llanero, bisonte, antílope americano, borrego cimarrón, ciervo rojo, venado cola blanca); carnívoros (coyote, lobo gris mexicano, zorra gris, zorra del desierto, lince, puma, jaguar), entre otros (De la Maza, et al., 2019; Macías-Duarte et al., 2016; Ceballos, \& Oliva, 2005).

iv. Participan en la infiltración de agua para la recarga de acuíferos (De la Maza et al., 2019). 
v. Mitigan los efectos del cambio climático al evitar la degradación de los suelos (De la Maza et al., 2019).

vi. Su extensión y conectividad con otros tipos de vegetación mantiene el flujo genético de la biodiversidad (De la Maza et al., 2019), como los bosques templados secos y selvas bajas caducifolias de los barrancos ubicados en la sierra Tarahumara, así como humedales de montaña, como los ubicados en el semidesierto chihuahuense.

vii. El paisaje vegetativo natural más extenso e importante del noroeste de Chihuahua.

No obstante, con la caída de la producción forestal de los bosques ubicados en la sierra Tarahumara de los municipios de Madera y Casas Grandes, en la década de 1970, además de la crisis económica regional y la presencia de diversas sequías, se han provocado cambios en la producción y en el desarrollo de nuevas alternativas de sobrevivencia de los pueblos de esta región.

Por lo anterior, alrededor de 1974, la familia Quezada ubicada en Mata Ortiz, desarrolló una alfarería con diseños basados en los colores y patrones geométricos de la cerámica de la cultura Casas Grandes-Paquimé, que se encuentra a $30 \mathrm{~km}$ de distancia del sitio arqueológico de Paquimé, y aproximadamente a $50 \mathrm{~km}$ de los sitios arqueológicos de las casas acantilado de Casas Grandes.

La técnica de alfarería de las familias de Mata Ortiz, se ha perfeccionado y transmitido a varias poblaciones de la zona, añadiendo un poco de arena en la mezcla de barro de diferentes colores y minerales (manganeso, óxido de cobre y barro negro) para evitar que se fragmente (MacCallum, 1994). Las ollas ya terminadas se pulen con rocas de canto rodado obtenidas de los escurrimientos que provienen de la sierra Madre Occidental. Para cocer las piezas, se utiliza estiércol seco de ganado regional como combustible y una maceta elaborada en áreas del sur de la República Mexicana para "tapar" y cocer las ollas. Los patrones geométricos y zoomorfos regionales son detallados con colores ocre y pintados con pinceles elaborados con cabellos humanos, que resultan muy precisos al pintar. Se logra una estética singular, que, además, es 
considerada como arte popular contemporáneo. Este es un producto de procesos socioeconómicos y culturales. Juan Quezada Celado es considerado precursor de esta estética contemporánea popular, quien recibió en 1999 el Premio Nacional de Ciencias y Artes en el área de Artes y Tradiciones Populares, que otorga el gobierno de la República Mexicana.

Para la segunda década del siglo xxI, la migración de poblaciones mestizas y de pueblos originarios se ha intensificado para participar como jornaleros en las zonas de agricultura de hortalizas, como chile y tomate, así como también de frijol, trigo, forraje de maíz y alfalfa. La fruticultura se concentra en el durazno, ciruelo, nogal, pera y manzano.

Estos cultivos son estimulados por los mormones y menonitas; así, las praderas naturales son sustituidas por este tipo de producción a lo largo de los municipios de San Buenaventura, Galeana, Nuevo Casas Grandes, Casas Grandes, Madera y Janos.

En mayo de 2017 participaban 2562 personas, según el Gobierno del Estado y datos del Programa de Atención a Personas Jornaleras Agrícolas Migrantes (ProJam), que provienen de los estados de Guerrero, Hidalgo, Oaxaca, Sinaloa, Veracruz y Zacatecas y del propio Chihuahua. Según datos de la licenciada Flor Ma. Vargas, responsable del Programa de Atención a la Niñez Migrante de la Dirección de Atención a la Diversidad y Acciones Transversales (Dadyat) de los Servicios Educativos del Estado de Chihuahua (Seech), se tienen identificados mixtecos, tlapanecos y mahuas del estado de Guerrero, así comop zapotecos, triquis y mazatecos del estado de Oaxaca.

\section{SÍNTESIS DE LOS PAISAJES CULTURALES DEL NOROESTE DE CHIHUAHUA}

El dinamismo y cambio que se presentan en los paisajes culturales de esta región del noroeste del estado de Chihuahua, que comprende ancestralmente al área geocultural Casas Grandes-Paquimé, contiene una diversidad patrimonial que puede observarse y analizarse de manera independiente. 
Al hacer, entonces, un intento por mostrar la diversidad de los paisajes culturales de la zona estudiada, encontramos que se construyen a partir de la concatenación patrimonial de tres tipos: Patrimonio cultural inmaterial, Patrimonio cultural material y Patrimonio cultural, biocultural y ecogeográfico (véase Tabla 1). Cada uno de ellos posee su valor, significado y singularidad, que le otorga la historia sociocultural y la región como construcción geográfica; asimismo, cada uno de los elementos culturales enunciados, se articulan para dar el sentido del complejo cultural llamado Paisajes Culturales de la Región Casas Grandes-Paquimé.

Tabla 1. Elementos patrimoniales de los paisajes culturales de la región

Casas Grandes-Paquimé

\begin{tabular}{|c|c|c|}
\hline $\begin{array}{l}\text { Patrimonio cultural } \\
\text { inmaterial }\end{array}$ & $\begin{array}{c}\text { Patrimonio cultural } \\
\text { material }\end{array}$ & $\begin{array}{c}\text { Patrimonio cultural, } \\
\text { biocultural y } \\
\text { ecogeográfico }\end{array}$ \\
\hline $\begin{array}{l}\text { Lenguaje (castellano-vasco) } \\
\text { 1. Lenguaje mixteco, tlapa- } \\
\text { neco, náhuatl, zapoteco, } \\
\text { triqui y mazateco. }\end{array}$ & $\begin{array}{l}\text { 1. Sitios de asentamiento } \\
\text { español. }\end{array}$ & $\begin{array}{l}\text { 1. Llanuras de acumulación } \\
\text { pie de monte con vege- } \\
\text { tación de pastos y masa } \\
\text { arbórea de semidesierto. }\end{array}$ \\
\hline $\begin{array}{l}\text { 2. Lenguaje extranjero: in- } \\
\text { glés y alemán. }\end{array}$ & $\begin{array}{l}\text { 2. Patrones y trazo urbano- } \\
\text { rural. }\end{array}$ & $\begin{array}{l}\text { 2. Llanuras aluviales en es- } \\
\text { currimientos superficiales. }\end{array}$ \\
\hline $\begin{array}{l}\text { 3. Formas de organización } \\
\text { social productiva. } \\
\text { 4. Oficios: vaquería, albañile- } \\
\text { ría especializada en adobe, } \\
\text { talabartería, carpintería, } \\
\text { herrería, constureros, } \\
\text { cocineras, sotoleros, aga- } \\
\text { veros, servicio doméstico, } \\
\text { ferrocarrileros, técnicos } \\
\text { forestales, entre otros. }\end{array}$ & $\begin{array}{l}\text { 3. Templos de misión. } \\
\text { 4. Arte sacro. } \\
\text { 5. Haciendas ganaderas. } \\
\text { 6. Edificios cívicos. } \\
\text { 7. Casas-habitación con } \\
\text { sistemas contructivos de } \\
\text { adobe, cal-canto y madera. } \\
\text { 8. Sitio de asentamiento } \\
\text { indígena. }\end{array}$ & $\begin{array}{l}\text { 3. Zonas de acumulación y } \\
\text { sedimentación de materia- } \\
\text { les aluviales en los escurri- } \\
\text { mientos superficiales. } \\
\text { 4. Planicies y llanuras con } \\
\text { praderas ricas en pastos. } \\
\text { 5. Humedales en cuencas } \\
\text { endorreicas (bolsones o } \\
\text { lagunas) y calderas volcá- } \\
\text { nicas muy erosionadas. }\end{array}$ \\
\hline
\end{tabular}

Continúa... 


\begin{tabular}{|c|c|c|}
\hline $\begin{array}{l}\text { Patrimonio cultural } \\
\text { inmaterial }\end{array}$ & $\begin{array}{c}\text { Patrimonio cultural } \\
\text { material }\end{array}$ & $\begin{array}{c}\text { Patrimonio cultural, } \\
\text { biocultural y } \\
\text { ecogeográfico }\end{array}$ \\
\hline $\begin{array}{l}\text { 5. Saberes: conocimientos } \\
\text { tradicionales derivados de } \\
\text { oficios; de origen mesoa- } \\
\text { mericano y árabe. } \\
\text { 6. Nuevas formas de produc- } \\
\text { ción y de propiedad. } \\
\text { 7. Fiestas patronales. } \\
\text { 8. Patrimonio gastronómico } \\
\text { y nuevas cocinas tradicio- } \\
\text { nales mestizas: basadas } \\
\text { en trigo, carne de res, } \\
\text { borrego, cabras, lácteos, } \\
\text { aves (guajolotes o pavo); } \\
\text { especias, nuevos frutales, } \\
\text { nuevos utensilios y tecno- } \\
\text { logías de conservación de } \\
\text { alimentos). } \\
\text { 9. Alfarería artesanal emer- } \\
\text { gente. } \\
\text { 10. Estética artesanal regio- } \\
\text { nal contemporánea }\end{array}$ & $\begin{array}{l}\text { 9. Acequias. } \\
\text { 10. Distribuidores. } \\
\text { 11. Presas de levante. } \\
\text { 12. Acequias derivadoras. } \\
\text { 13. Estanques. } \\
\text { 14. Abrevaderos. } \\
\text { 15. Aljibes. } \\
\text { 16. Pozos y brocales. } \\
\text { 17. Diques. } \\
\text { 18. Pilas. } \\
\text { 19. Estaciones de ferrocarril. } \\
\text { 20. Patrimonio edificado } \\
\text { escolar. }\end{array}$ & $\begin{array}{l}\text { 6. Humedales de manan- } \\
\text { tiales y aguas termales } \\
\text { superficiales. En llanuras } \\
\text { del semidesierto y de la } \\
\text { montaña. } \\
\text { 7. Biodiversidad endémica: } \\
\text { aves de pastizales, perrito } \\
\text { de pradera, bisonte, bo- } \\
\text { rrego cimarrón, berrendo, } \\
\text { puma, oso negro, jaguar, } \\
\text { jaguarundi, lince, guajolote } \\
\text { silvestre, entre otros. } \\
\text { 8. Saberes: conocimientos } \\
\text { tradicionales de mestizos, } \\
\text { en el uso gastronómico, } \\
\text { de bosques templados } \\
\text { secos y de flora y fauna } \\
\text { del semidesierto, de suelos } \\
\text { y minerales, manejo de } \\
\text { ganado, cacería de fauna } \\
\text { endémica. } \\
\text { 9. Saberes: conocimientos } \\
\text { tradicionales adaptados re- } \\
\text { gionalmente por migrantes } \\
\text { extranjeros de menonitas y } \\
\text { mormones. } \\
\text { 10. Saberes: conocimientos } \\
\text { tradicionales adaptados } \\
\text { regionalmente por migran- } \\
\text { tes de pueblos indígenas } \\
\text { del sur de la República } \\
\text { Mexicana. } \\
\text { 11. Saberes: conocimientos } \\
\text { tradicionales adaptados } \\
\text { regionalmente para el } \\
\text { manejo y uso del agua, } \\
\text { subterránea y superficial. }\end{array}$ \\
\hline
\end{tabular}




\section{CONCLUSIONES}

En los paisajes culturales de la región del noroeste o Casas Grandes-Paquimé, se procesan distintas acciones humanas que, a través del tiempo y de este territorio, se manifiestan en distintos elementos patrimoniales. Por ello, la producción de los paisajes culturales de esta zona es compleja y requiere de una visión transdisciplinaria de tipo territorial e histórica, cultural, medioambiental, económica y política.

Debido a esto, la posibilidad de agrupar esta diversidad cultural en la noción geográfica regional de paisajes culturales ofrece oportunidades distintas en el desarrollo de políticas públicas transversales, donde la cultura, la educación, el turismo, la economía basada en la diversidad cultural-productiva y, por tanto, la potencialidad paisajística cultural del área, permiten visualizar que es posible el desarrollo sustentable, es decir, que sea "ecológicamente adecuado, económicamente viable, socialmente justo, culturalmente apropiado y con un enfoque científicamente holístico" (Shiva, 1993).

\section{REFERENCIAS}

\section{Entrevista}

Comunicación telefónica con la licenciada Flor Ma. Vargas, responsable del Programa de Atención a la Niñez Migrante de la Dirección de Atención a la Diversidad y Acciones Transversales (Dadyat) de los Servicios Educativos del Estado de Chihuahua (Seech); miércoles 27 de marzo del 2019.

\section{Documentos institucionales}

Fondo Mundial para la Naturaleza (wwF) (1996). La maravilla de los humedales. Ramsar. Recuperado de: www.ramsar.org.ir (s./f.). La lista Ramsar de Humedales de Importancia Internacional. Ramsar. Recuperado de http://archive.ramsar.org/cda/ramsar/display/main/main.j.jp?zn=ramsar\&cp=1-31-218_4000_2__ 
idesmac/DCAAAC/ALLinfo (2018). Agenda Común para la Conservación y el Desarrollo de la Sierra Tarahumara. México: Proyecto Tarahumara Sustentable/Fondo para el Medio Ambiente Mundial (GEF)/Comisión Nacional de Áreas Naturales Protegidas (Conanp)/Fondo Mundial para la Naturaleza (wwF).

Organización de las Naciones Unidas para la Educación, la Ciencia y la Cultura (Unesco) (2003). Convención para la salvaguarda del Patrimonio Inmaterial. Recuperado de http://portal.unesco. org/es/ev.php-URL_ID=17716\&URL_DO=DO_TOPIC\&URL_ SECTION=201.html

Sistema Importante Agrícola Mundial (Sipam) (2002). Recuperado de https://www.azp.cdmx.gob.mx/s torage/app/media/SIPAM1.pdf

\section{Bibliografía}

Aboites Aguilar, L. (1995). Norte precario. Poblamiento y colonización en México (1760-1940). México: El Colegio de México (Colmex)/Centro de Investigaciones y Estudios Superiores en Antropología Social (CIESAS).

Arnold, D. (2000). La naturaleza como problema histórico. El medio, la cultura y la expansión de Europa. México: FCE.

Barragán, E., Ortiz, J., \& Toledo, A. (2007). Patrimonios cuenca del río Tepalcatepec. Zamora, Michoacán: El Colegio de Michoacán.

Baudrillard, J. (1983). El espejo de la producción. México: Gedisa. Bautista Flores, E., y Sánchez Carlos, O. A. (2018). Diáspora transnacional de comunidades entre menonitas de México y Brasil. Revista Mexicana de Sociología, 4, 739-765.

Bertrand, G. (1987). Construir la geografía física. Posición. Revista de Crítica y Análisis Espacial, 3(4-5).

Boehm Schoendube, B. (2001). El lago de Chapala: su ribera norte.

Un ensayo de lectura del paisaje cultural. Relaciones, 22(85), 57-84.

---- (2005). Buscando hacer ciencia social. La antropología y la ecología cultural. Relaciones, 26(102), 63-128. 
Bonfil Batalla, G. (1991). Pensar nuestra cultura. México: Alianza Editorial.

Braniff, B. (1997). Paquimé: pequeña historia de las Casas Grandes. En B. Braniff, B. (Coord.), Papeles norteños. México: Colección Científica del INAH/Conaculta.

---- (2000). Sistemas agrícolas prehispánicos en la Gran Chichimeca. En M. Hers, J. L. Mirafuentes, M. Dolores Soto, \& M. Villabueno (Coords.), Nómadas y sedentarios en el norte de México. México: UNAM/IIA/IIE/IIH.

Braudel, F. (1969). La larga duración. Historia y Ciencias Sociales. Madrid: Alianza Editorial.

---- (1991). Las civilizaciones actuales. Estudio de historia económica y social. México: Red Editorial Iberoamericana.

----- (1997). El Mediterráneo y el mundo mediterráneo en la época de Felipe II. México: FCE.

Brown, D. F. (1999). El paisaje cultural y los mayas yucatecos. Quivera, 1, 75-86.

Brumet, R. (1974). Análisis de los paisajes y semiología. En J. Gómez Mendoza, J. Muñoz, \& N. Ortega (Coords.), El pensamiento geográfico. Estudio comparativo y antología de textos (pp. 485-493). Barcelona: Alianza Editorial.

Capel, H. (2002). La morfología de las ciudades. Sociedad, cultura y paisaje urbano. Barcelona: Ediciones del Serval.

Ceballos, G., \& Oliva, G. (2015). Los mamíferos silvestres de Méxi-

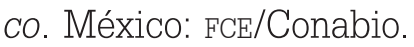

Cervantes, B. J. (1993). Modelo geosistémico para la prospección, uso y manejo del medio y de los recursos naturales. Boletín del Instituto de Geografía, 19, 90-105.

Cramaussel, C. (1989). Transformaciones en el medio ambiente, una laguna desaparecida en el sur del estado de Chihuahua. Suma, 1.

Dansereau, P. (1981). Interioridad y medio ambiente. México: Nueva Imagen.

De la Maza Benignos, M., Banda Villanueva, I., Mendoza González, G., Leal Nares, O. A., \& Rendón Herrera, G. (2019). Reporte del estado de los pastizales del desierto chihuahuense. Una 
perpectiva de gestión. Chihuahua, México: Pronatura Noreste, A. C./American Bird Conservancy.

De la Peña, G. (1991). Los estudios regionales y la antropología social. En P. Pérez Herrero (Coord.), Región e historia en México. Antologías universitarias (pp. 123-162). México: Instituto Mora.

Di Peso, C. et al. (1974). Casas Grandes, A Fallen Trading Center of the Gran Chichimeca. Flagstaff, Arizona: Amerind Foundation Publications.

Doolitte, W. (2014). Canales de riego en el México prehistórico. La secuencia del cambio tecnológico. Chapingo, Estado de México: Universidad Autónoma de Chapingo/Museo Nacional de Agricultura/Departamento de Irrigación.

Douglas, M. (1996). La aceptabilidad del riesgo según las ciencias sociales. Barcelona: Paidós Studio.

Fábregas Puig, A. (1992). El concepto de región en la literatura antropológica. Tuxtla Gutiérrez, Chiapas, México: Instituto Chiapaneco de Cultura.

----- (2003). Reflexiones desde la tierra nómada. Guadalajara, México: Universidad de Guadalajara/Colegio de San Luis.

Fernández Christlieb, F. (2005). Algunas fuentes para el estudio de la geografía cultural. En C. Téllez, \& P. E. Olivera (Coords.), Debates en la geografía contemporánea. Homenaje a Milton Santos (pp. 85-104). México: Colmich/Embajada de Brasil/Facultad de Filosofía y Letras-Universidad de Guadalajara.

----- (2006). La pintura geografica en el siglo Xvi y su relación con una propuesta actual de la definición de paisaje. Geocrítica. Scripta Nova. Revista Electrónica de Geografía y Ciencias Sociales, 10(218), 69.

Forman Richard, T. (2000). The Ecology of Landscapes and Region. Cambridge, Inglaterra: Cambridge University Press.

Foster, S. M. (1992). Arquelogía del valle de Casas Grandes: sitio Paquimé. En A. Márquez-Alameda (Coord.), Historia general de Chihuahua 1. Geología, geografía y arqueología (pp. 229282). Ciudad Juárez, Chihuahua, México: uAcj/Gobierno del Estado de Chihuahua. 
Gamboa Carrera, E. (2001). Sistemas de retención de suelo o irrigación de la cultura Casas Grandes. Chihuahua, México: Centro INAH/Mecanoescrito.

Gamboa Carrera, E., \& Mancera-Valencia, F. J. (2008). The Cultural Landscapes of Cliff Houses in the Sierra Madre Occidental, Chihuahua. In E. M. McBrinn, \& L. D. Webster (Coords.), Archaeology withouh Borders. Contac, Comerce and Change in the U. S. Southwest and Northwestern Mexico (pp. 355-364). Denver, EU: Proceedigns of the 2004 Southwets Symposium. University Press of Colorado.

García Martínez, B., Jiménez, A., \& Thiébault, V. (Edits.) (2008).

Patrimonio y paisajes culturales. Michoacán, México: El Colegio de Michoacán.

García Martínez, B. (1997). La organización colonial del espacio: un tema mexicano de geografía. Memorias del II Simposio Panamericano de Historia; 25 al 29 de septiembre de 1995. México: IPGH.

---- (1998). En busca de la geografía histórica. Relaciones, 19(75), 27-58.

----- (2003). Ríos desbordados y pastizales secos: un recorrido de contrastes por los caminos ganaderos del siglo xvIII novohispano. En B. García Martínez, \& M. Rosario Prieto (Coords.), Estudios sobre historia y ambiente en América II. Norteamérica, Sudamérica y el Pacífico (pp. 247-278). México: Colmex/IPGH.

Geissert, D., \& Rossignol, J. (1987). La morfoedafología en la ordenación de los paisajes rurales. Xalapa, México: INREB/orstom.

Giddings, L., Chiappy, C., Soto, M., \& Gama, L. (1996). Modificaciones,ecológico-paisajistas del estado de Veracruz, México. Investigaciones Geográficas Boletín, 33, 31-49.

González de Molina, M., \& Martínez Alier, J. (Eds.) (2001). Naturaleza transformada. Estudios de historia ambiental transformada. Barcelona: Icaria/Ecología Human.

Gould, P. (1975). Las imágenes mentales del espacio geográfico. En J. Gómez Mendoza, J. Muñoz, \& N. Ortega, N. (Coords.), El pensamiento geográfico. Estudio comparativo y antología de textos (pp. 477-484). Barcelona: Alianza Editorial. 
Graff-Montero, S., Anta-Fonseca, S., Bezaury-Creel, J., \& ArellanoGuillermo, A. (2015). Protocolo para la implementación de los paisajes bioculturales en México. México: Comisión Nacional de Áreas Naturales Protegidas (Conanp)/Agencia Francesa de Desarrollo/Nature Conservancy.

Guerrero Galván, L. R. (2016). A propósito del aniversario porfiriano. Una aproximación acerca de las compañías deslindadoras en tiempos del Porfiriato. Revista Latinoamericana de Derecho Social, 22.

Guevara Sánchez, A. (1986). Arqueología del área de las Cuarenta Casas, Chihuahua. Colección Científica INAH.

Hard, R. J., \& Roney, J. R. (1998). Una investigación arqueológica de los sitios Cerros con Trincheras del Arcaico Tardio en Chihuahua, México. Chihuahua, México: inAH/Conaculta.

Hernández Díaz, K. M. (2016). Producción ganadera a finales del siglo XIX. Las haciendas de Luis Terrazas Fuentes. En S. Pérez Martínez (Coord), Agostaderos y ganado. Tradición y patrimonio de Chihuahua. 80 años de historia, 1936-2016 (pp. 22-31). Chihuahua, México: Unión Ganadera Regional/INAH.

Hirich, E., \& O'Hanion, H. (Eds.) (1995). The Antropology of Landscape. Oxford, Inglaterra: Claredon Press. Citado en Brown, D. F. (1999). El paisaje cultural y los mayas yucatecos. Quivera, $1,75-86$.

Hoffman, O. (1993). Rumbo y paisajes de Xico. Geografía de un municipo de la sierra de Veracruz. Instituto de Ecología. Xalapa, México: oRsTom.

Jodelet, D. (2016). On Structuring and Outlining Processes in the Study of Social Representation. Papers on Social Representations, 25(2), 2.1-2.11.

LaMond Tullis, E. (2012). Los colonizadores mormones en Chihuahua y Sonora. Recuperado de https://www.lds.org/bc/content/ areas/mexico/pdf/los-colonizadores-mormones-de-chihuahuay-sonora.pdf

Le Roy Landurie, E. (1978). Montaillou. Promised Land of Error. Nueva York: Vintage Books Edition. 
Loera González, J. J. (2015). La construcción de los buenos vivires; entre los márgenes y tensiones ontológicas. Polis, 40. Recuperado de http://polis.revues.org/10654

Luhmann, N. (1998). Sociología del riesgo. México: Universidad Iberoamericana/Tristana Editores.

Luis Gómez, A. (1980). El geógrafo español. ¿Aprendiz de brujo? Algunos problemas de la geografía del paisaje. Geocrítica. Cuadernos Críticos de Geografía Humana, 25.

MacCallum, S. H. (1994). Pioneering and Art Movement in Northern Mexico: the Potters of Mata Ortiz. KIVA. The Journal of Southwestern Anthropology and History, 60(1), 71-92.

MacCloung de Tapia, E. (1979). Ecología y cultura en Mesoamérica. México: unam.

MacCloung de Tapia, E., \& Tapia Rencillas, H. (1995). Un estudio de paisaje y patrón de asentamiento prehispánico en la región de Teotihuacan, México. Investigaciones Geográficas, 4, 13-37. Macías-Duarte, A., Panjabi, A. O., \& Aguirre Calderón, C. E. (2016). Compartiendo sus agostaderos con las aves de pastizal. Colorado, EU: Rocky Mountain Bird Observatory (RMBO).

Mancera-Valencia, F. J. (2016). Descolonización de las epistemologías locales-regionales desde la pedagogía sociocultural (tesis doctoral). Chihuahua, México: Instituto de Pedagogía Crítica.

---- (2016). Humedales e irrigación: geohistoria de los paisajes culturales en el desierto. Internacional Carl Lumholtz. Sociedad, cultura y medio ambiente: retos, transformaciones y permanencias. Simposio 12: Paleodieta, paleoambiente y paleopaisaje en el norte de México del II Congreso de la Escuela Nacional de Antropología e Historia del Norte de México (EnAHnM), Instituto Nacional de Antropología e Historia (INAH), Unidad de Antropología de la Universidad Autónoma de Zacatecas (UAz) y Centro de Investigación y Docencia (CiD). Chihuahua, México. Mancera-Valencia, F. J., Romero Gutiérrez, R. I., \& Rey Chávez, L. (2015). Los paisajes culturales del desierto: acequias, huertos y humedales. En F. J. Mancera-Valencia (Coord.), Patrimonio biocultural de Chihuahua (pp. 267-289). Chihuahua, México: Ichicult/Conaculta. 
Márquez-Alameda, A. (1992). Sobre los pobladores más antiguos del actual estado de Chihuahua. En A. Márquez-Alameda (Coord.), Historia general de Chihuahua 1. Geología, geografía y arqueología (pp. 105-129). Ciudad Juárez, Chihuahua, MéxiCo: UACJ/Gobierno del Estado de Chihuahua.

Mateo, J. (1982). Geografía de los paisajes. La Habana, Cuba: André Voisin/Empresa Nacional de Producción y Servicios del Ministerio de Educación Superior.

Mateo Rodríguez, J. M., \& Ortiz Pérez, M. A. (2001). La degradación de los paisajes como concepción teórico-metodológica. Serie Varia, 1, 9-40.

Mendiola Galván, F. (2008). La expresión simbólica de nómadas y sedentarios. En A. Guevara Sánchez, \& F. Mendiola Galván (Coords.), Geometrías de la imaginación. Diseño e iconografía. Chihuahua, México: Conaculta.

Miller, A. M., Mancera, A. B., Gringrich, R., \& Curiel, D. (1999). Barranca de Sinforosa. Bird Studies. Chihuahua, México. Final Report. Chihuahua, México: Sierra Madre Alliance.

Moscovici, S. (1985). Psicología social I y II. Barcelona: Paidós.

Olmos Loya, A. (2001). La representación social de la enfermedad mental: un estudio con el personal del hospital Psiquiátrico de Chihuahua (tesis). Chihuahua, México: Escuela Libre de Psicología.

Orozco, V. (1997). Los apaches: una nación indomable. En B. C. Braniff (Coord.), Papeles norteños (Colección Científica. Serie Antropología Social). México: INAH.

Parks, W. (1993). The Miracle of Mata Ortiz, Juan Quezada and the Potters of Northern Chihuahua. Riverside, Eu: The Coulter Press.

Pérez Taylor, R., Olmos Aguilera, M., \& Salas Quintanal, H. (2007). Antropología del desierto: paisaje, naturaleza y sociedad. México: El Colegio de la Frontera Norte/unAm/siBE.

Pool, D. B., Panjabim A. O., Macías-Duarte, A., \& Solhjem, D. M. (2014). Rapid Expansion of Croplands in Chihuahua, México Threatens Declining North American Grassland Bird Species. Biological Conservation, 170, 274-281. 
Riábchikov, A. M. (1976). Estructura y dinámica de la esfera geográfica. Moscú: Editorial MIs.

Rodríguez Salazar, T. (2003). El debate de las representaciones sociales en la psicología social. Relaciones. Estudios de Historia y Sociedad, 93, 51-80.

Romero Contreras, A. T. (2001). Origen y desarrollo de la geografía cultural. En A. T. Romero Contreras et al. (Coords.), Espacio geográfico (pp. 13-40). Estado de México: Facultad de Geografía de la UNAM.

Ruiz Guadalajara, J. C. (2003). Representaciones colectivas, mentalidades e historia cultural: a propósito de Chartier y el mundo como representación. Relaciones. Estudios de Historia y Sociedad, 93, 17-50.

Sauer, O. C. (1925). The Morphology of Landscape. Berkeley, Eu: University Press.

(1931). La geografía cultural. En J. Gómez Mendoza, J. Muñoz, \& N. Ortega, N. (Coords.), El pensamiento geográfico. Estudio comparativo y antología de textos (pp. 349-354). Barcelona: Alianza Editorial.

----- (1945). Introducción a la geografía histórica. En C. Cortez (Coord.), Geografía histórica. Antologías universitarias (pp. 3552). México: Instituto de Investigaciones Dr. José Ma. Luis Mora.

Taylor Hansen, L. D. (2005). Las migraciones menonitas al norte de México entre 1922 y 1940. Revista Migraciones Internacionales. El Colegio de la Frontera Norte, 3(1), 5-31. Recuperado de http://www.scielo.org.mx/pdf/migra/v3n1/v3n1a1.pdf

Tinoco Ojanguren, R., \& Bellato, L. (Comps) (2006), Representaciones sociales de la pobreza en Chiapas. San Cristóbal de las Casas, México: Secretaría de Desarrollo Social/El Colegio de la Frontera Sur.

Toledo, V. M. (1994). Tres problemas en el estudio de la apropiación de los recursos naturales y sus repercusiones en la educación. En E. Leff (Comp.), Ciencias sociales y formación ambiental (pp. 157-178). México: Gedisa Editorial/Centro de Investigaciones Interdisciplinarias e Humanidades de la unAM. 
Tortolero Villaseñor, A. (Coord.). (1996). Tierra, agua y bosques: historia y medio ambiente en el México central. México: Centre Francais d'études Mexicaines et Centraméricaines/Universidad de Guadalajara/Potrerillos Editores.

Tricart, J., \& Killian, J. (1982). La ecogeografía y la ordenación territorial del medio físico. Barcelona: Anagrama.

Turok, M. et al. (1999). Artes de México, núm. 45. Cerámica de Mata Ortiz. México: Artes de México.

Urquioloa Permisan, J. I. (1999). Estructura urbana y agua. La fase del asentamiento de Querétaro: el núcleo, huertas, labores y conducción de agua. En S. Pérez Toledo et al. (Eds.), Las ciudades y sus estructuras. Población, espacio y cultura en México. México: UAM.

Weaver, T. (1992). Los indios del gran suroeste de los Estados Unidos. Madrid: Colecciones Mapfre.

West, R. C. (1979). Carl Sauer's Fieldwork in Latin America. Ann Arbor, eu: Department of Geography Syracuse University.

Zemelman, H. (1989). Crítica epistemológica de los indicadores. México: El Colegio de México. 